BioRxiv Preprint

\title{
A model of colour appearance based on efficient coding of natural images
}

\author{
Jolyon Troscianko*1 \& Daniel Osorio²
}

\author{
${ }^{1}$ Centre for Ecology \& Evolution, University of Exeter \\ ${ }^{2}$ School of Life Sciences, University of Sussex \\ Corresponding author: jt@jolyon.co.uk
}

\section{ORCIDs;}

JT: 0000-0001-9071-2594

DO: 0000-0002-5856-527X

\section{Abstract}

1 An object's colour, brightness and pattern are all influenced by its surroundings, and a number of 2 visual phenomena and "illusions" have been discovered that highlight these often dramatic effects.

3 Explanations for these phenomena range from low-level neural mechanisms to high-level processes that incorporate contextual information or prior knowledge. Importantly, few of these phenomena can currently be accounted for when measuring an object's perceived colour. Here we ask to what extent colour appearance is predicted by a model based on the principle of coding efficiency. The model assumes that the image is encoded by noisy spatio-chromatic filters at one octave separations, which are either circularly symmetrical or oriented. Each spatial band's lower threshold is set by the contrast sensitivity function, and the dynamic range of the band is a fixed multiple of this threshold, above which the response saturates. Filter outputs are then reweighted to give equal power in each channel for natural images. We demonstrate that the model fits human behavioural performance in psychophysics experiments, and also primate retinal ganglion responses. Next we systematically test the model's ability to qualitatively predict over 35 brightness and colour phenomena, with almost complete success. This implies that contrary to high-level processing explanations, much of colour appearance is potentially attributable to simple mechanisms evolved for efficient coding of natural images, and is a basis for modelling the vision of humans and other animals. 


\section{$\underline{\text { Key words }}$}

vision, visual modelling, colour appearance, visual illusions, colour constancy

\section{Introduction}

The colour and lightness of objects cannot be recovered directly from the retinal image of a scene, but depends upon neural processing by low-level spatial filters and feature detectors along with long-range and top-down mechanisms that incorporate contextual information and prior knowledge about the visual world (Wandell 1995; Brainard and Freeman 1997; Witzel et al. 2011; Bloj, Kersten, and Hurlbert 1999). Ideally, image processing achieves lightness and colour constancy allowing us to see colour and form veridically - but inevitably it produces visual effects and illusions, which give insight into the underlying mechanisms. Thus, the surroundings of an object affect its lightness or colour in several ways. For example, assimilation and induction effects shift appearance towards that of neighbouring colours (White 1979), whereas simultaneous contrast increases the difference between an object and the surround, and in contrast induction the surround affects the contrast of a pattern (Chubb, Sperling, and Solomon 1989; Brown and MacLeod 1997). The crispening effect - where contrasts close to the background level are enhanced - encompasses all three of these phenomena (Whittle 1992; Kane and Bertalmío 2019). Related effects in colour vision include the Abney, Bezold-Brücke, Hunt, and Stevens effects, where colours, colourfulness and contrasts shift with saturation and brightness (Fairchild 2013).

Neural mechanisms have been proposed to account for some of the foregoing phenomena, for example Mach Bands can be attributed to lateral inhibition (Ratliff 1965), brightness induction to spatial filtering in the primary visual cortex (Blakeslee and McCourt 2004), and colour constancy to photoreceptor adaptation (Judd 1940; Foster 2011) or to cortical processing (Roe et al. 2012) - but these accounts are controversial, and some effects are not easily explained (Brown and MacLeod 1997; Whittle 1992; Adelson 2000). Moreover, the lack of a comprehensive account of colour appearance limits the accuracy of the models that are typically used in design, industry and research (Hunt 2005a; Fairchild 2013).

Although photoreceptor adaptation and lateral inhibition do partly account for colour constancy and simultaneous contrast effects, their primary function is probably better understood as allowing the visual system to efficiently encode images of natural scenes, which have a large dynamic range and a high degree of statistical redundancy. Coding efficiency, which allows the brain to make optimal use of limited neural bandwidth and metabolic energy, is a key principle in early visual processing (Atick and Redlich 1992; Barlow 1961; Laughlin 1981; Ruderman, Cronin, and Chiao 1998; 
Simoncelli and Olshausen 2001), and here we ask how a model based on this principle might account for colour appearance.

The optimal (maximum entropy) code for natural images, as specified by their spatial autocorrelation function (i.e. second-order image statistics), approximates a Fourier transform (Bossomaier and Snyder 1986; Baddeley et al. 1997), which is physiologically unrealistic. Efficient codes can however be defined for circularly symmetrical Difference of Gaussian (DoG) or oriented Gabor-function filters, which respectively resemble the receptive fields of retinal ganglion cells and the simple cells of mammalian visual cortex (Daugman 1985; Enroth-Cugell and Robson 1966; Marĉelja 1980; Simoncelli and Olshausen 2001). In an early study, Laughlin and his co-workers (Laughlin 1981; Srinivasan et al. 1982) found that the contrast response functions and the centresurround receptive fields of fly (Lucilia vicina) large monopolar cell (LMC) neurons - which are directly post synaptic to the photoreceptors - produce an efficient representation of natural images for the noise present the insect's photoreceptor responses. Specifically, synaptic amplification at the receptor to LMC synapse and lateral inhibition between receptor outputs, give a neural code that quantitatively accords with the methods of histogram equalization and predictive coding that are used by data compression algorithms (Srinivasan et al. 1982). The centre-surround receptive fields of vertebrate retinal ganglion cells are comparable to those of fly monopolar cells (Tadmor and Tolhurst 2000), while the simple cells in visual cortex generate an efficient code for natural image statistics (Field 1987; Simoncelli and Olshausen 2001).

Our aim here is not to simulate biological vision precisely, but to model efficient coding by physiologically plausible spatial filters. We describe a Spatiochromatic Bandwidth Limited (SBL) model of early vision, which uses luminance and chromatic spatial filters at octave separations to cover the detectable range of spatial frequencies (Figures 1-3). Three parameters specify the model, namely the spatial autocorrelation function (power spectrum) of natural images, noise in the retinal signal, and the channel bandwidth - or number of distinguishable response states (Figure 1; (Laughlin 1981)). The first of these parameters is given by image statistics, the second by physiological or psychophysical measurements, and the third is estimated from psychophysical data on the crispening effect (Figure 3a; (Whittle 1992)). As the model predicts colour and lightness in naturalistic images, and accounts for various visual phenomena and illusions it offers a framework for understanding neural image processing, and is a starting point for simulating colour appearance for humans and other species. 


\section{The Model}

The SBL model is comparable to other models of early vision that have been proposed to account for lightness and colour perception. These include MIRAGE (Watt and Morgan 1985), which uses non-oriented DoG filters, and the oriented difference of gaussians model (Blakeslee and McCourt 2004), which uses orientation-sensitive filters. The model differs from its predecessors in that to achieve efficient coding of natural images the gain and dynamic range (i.e. contrast response function) of neural channels vary with spatial frequency - as specified by the contrast sensitivity threshold - with gain normalised to natural scene statistics so that on average the output has equal power in each spatial channel.

The model is implemented as follows (Figures 1,2). $i$ ): The image is filtered with a set of spatial filters at one octave separations. These filters are either circularly symmetrical difference of Gaussian (DoG) functions (Enroth-Cugell and Robson 1966) or Gabor functions at four orientations (Daugman 1985). The filtering process differs from convolution in that it applies a Michelson contrast to centre versus surrounds. The three spectral classes of filter correspond to those in human vision, namely achromatic/luminance with centre and surround receiving the same spectral inputs, blue - yellow, and red - green with centre and surround receiving opposite spectral inputs. ii): The lower threshold $(\alpha)$ for the filter is set by the psychophysical contrast sensitivity at the filter's centre frequency (based on contrast sensitivity functions, [CFSs], Mullen 1985; Kim, Mantiuk, and Lee 2013). $\alpha$ is subtracted from image contrasts, which is consistent with human psychophysics (Kulikowski 1976). The filters' contrast response function is linear over a limited dynamic range to an upper threshold $(\beta)$, which is a fixed multiple, $\varepsilon$, of $\alpha$. $\varepsilon$ corresponds to the number of contrast levels that can be encoded (i.e. channel bandwidth or response states; (Laughlin 1981)); (Figures 1,2). Thus, for $\varepsilon=10$, the contrast saturation threshold is 10 times the activation threshold for each filter. As $\varepsilon$ is equal for all channels, high sensitivity filters encode a smaller range of image contrasts than low sensitivity filters (Figure 2b). We estimated $\varepsilon$ by fitting the model to Whittle's (1992) psychophysical measurement of the crispening effect (Figure 3a, 4). iii) Signal power in each channel is normalised to that of the filter's response to a natural scene, thereby whitening the average spatial frequency power spectrum of the output (Carandini and Heeger 2012). iv) Filter outputs are summed to recover their representation of the original image, which can be compared to human perception of the image.

For the red-green and blue-yellow chromatic channels, we make the assumption, consistent with neurophysiology (Solomon and Lennie 2007; Conway 2001), that the filters are less orientation selective than for luminance channels and use only DoG filters (but see Shapley, Nunez, and 
125 Gordon 2019). The bandwidth of the red-green channel equals that of the luminance DoG signal, 126 which produces plausible results (Figure 1 and below). However, if the blue-yellow channel has the 127 same bandwidth $(\varepsilon)$, its low contrast sensitivity (Figure 2a) means that it fails to saturate in natural 128 scenes. We therefore reduced $\varepsilon$ to give an equal proportion of saturated pixels in natural images for 129 red-green and blue-yellow channels.

131 An implementation of the SBL model is provided as supplementary material for use with ImageJ, a 132 free, open-source image processing platform (Schneider, Rasband, and Eliceiri 2012) and the 133 micaToolbox (Troscianko and Stevens 2015; Berg, Troscianko, et al. 2020). 
bioRxiv preprint doi: https://doi.org/10.1101/2022.02 22 481414 this version posted February 23, 2022. The copyright holder for this preprint (which was not certified by peer review) is the author/funder, who has granted bioRxiv a license to display the preprint in perpetuity. It is made available under aCC-BY 4.0 International license.

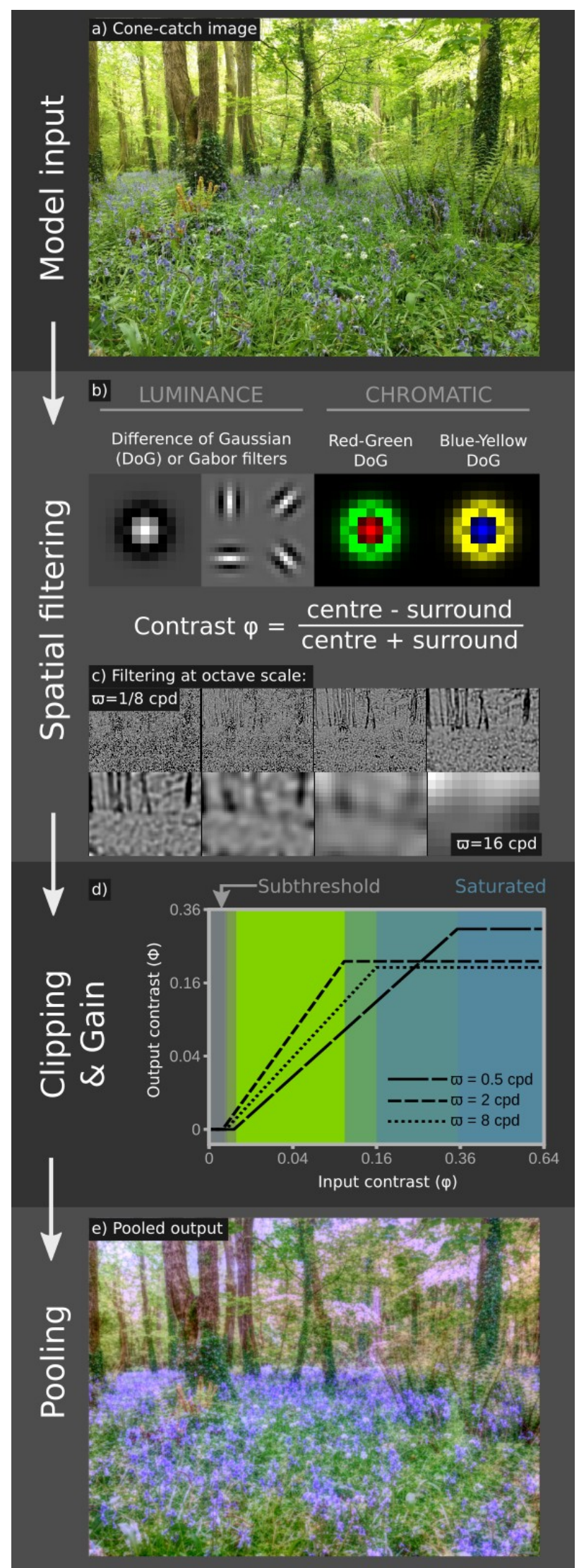

Figure 1. Overview of the Spatiochromatic Bandwidth Limited (SBL) model. The model uses a cone-catch image (a, Appendix), which is filtered by either DoG or Gabor kernels for luminance channels, and DoG kernels for chromatic channels (b). Contrasts are converted to Michelson contrasts (c. showing luminance DoG outputs), then clipping and gain processes are applied (d. Figure 2), and the spatial filters are pooled to create the output (e). Output colours are not scaled to sRGB space. 
bioRxiv preprint doi: https://doi.org/10.1101/2022.02.22.481414; this version posted February 23, 2022. The copyright holder for this preprint (which was not certified by peer review) is the author/funder, who has granted bioRxiv a license to display the preprint in perpetuity. It is made available under aCC-BY 4.0 International license.

Clipping: SUBTHRESHOLD: contrasts are too small to detect (+/-)

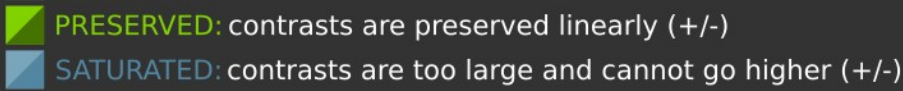

a

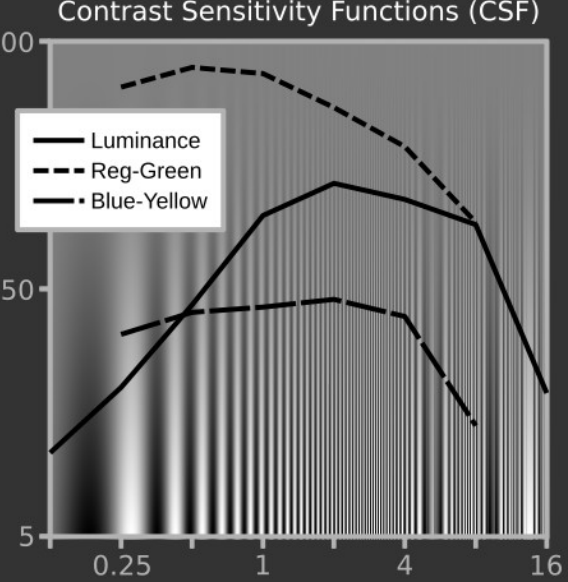

Spatial Frequency ( $\varpi, c p d)$
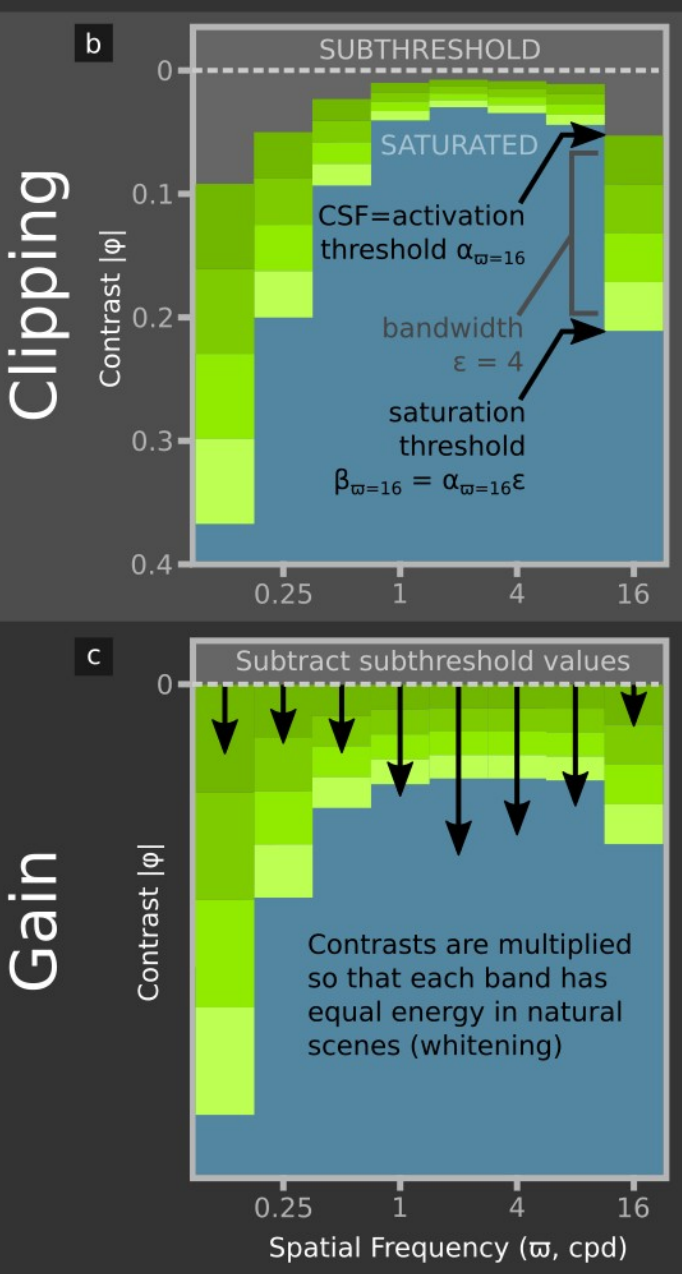

d) Input image
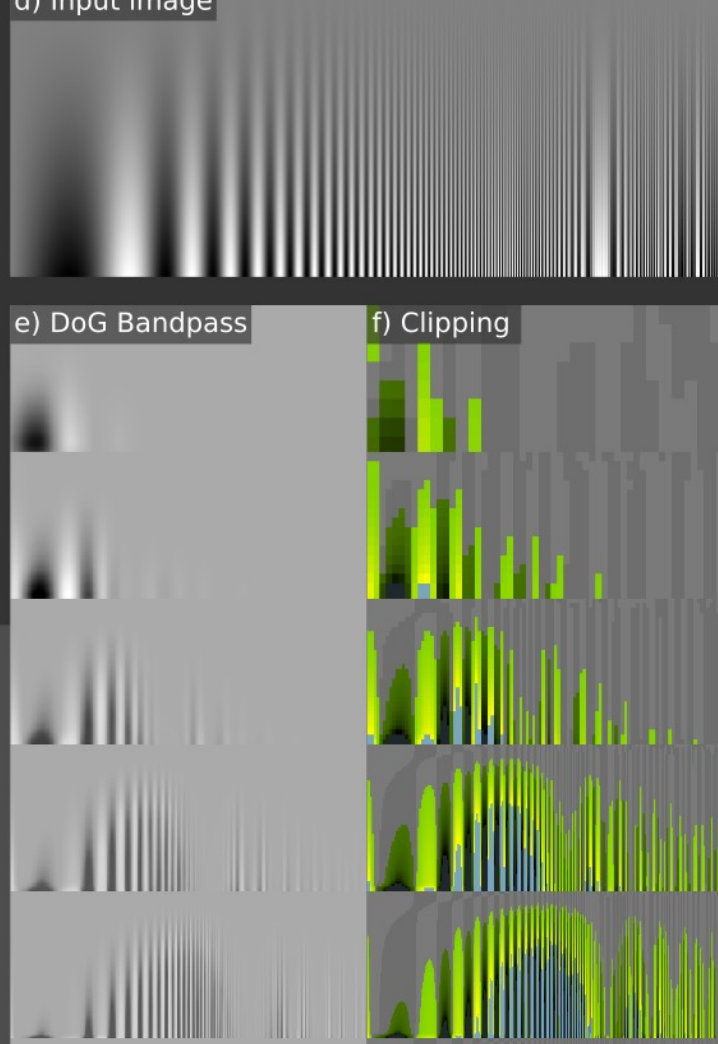

$+$
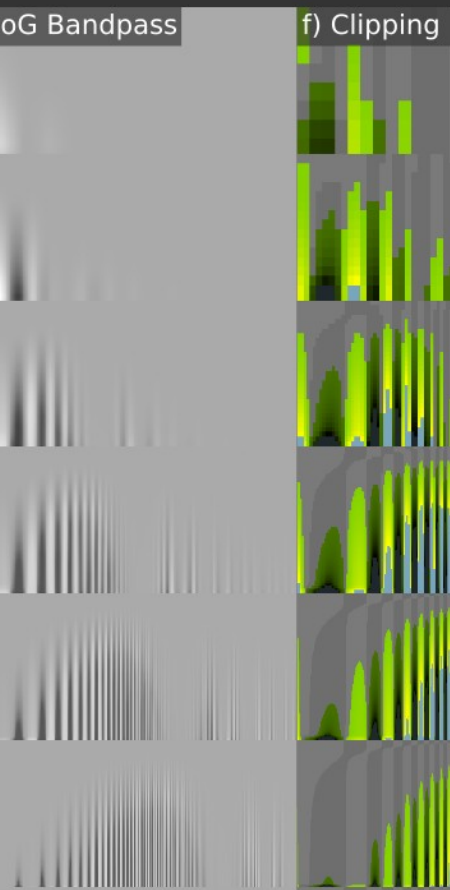

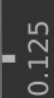

$\stackrel{\text { กิ }}{0}$

$=$ เก

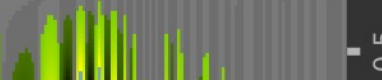

흔

$-\rightarrow \frac{B}{C}$

$+\frac{1}{3}$

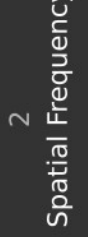

$\checkmark$

$\infty$

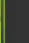

$\stackrel{\bullet}{\sim}$

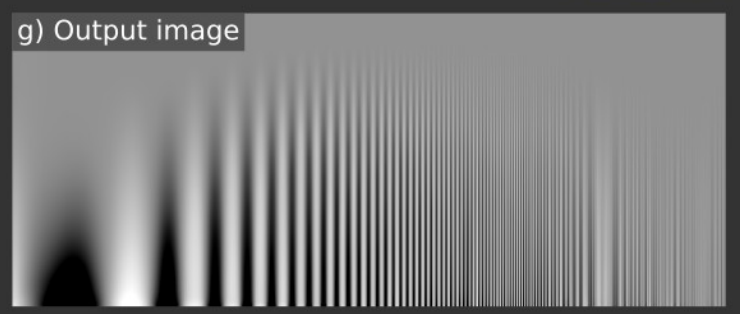

Figure 2. Dynamic range clipping and gain adjustment by the SBF model. a) human luminance and chromatic detection thresholds for sinewave gratings (Kim, Mantiuk, and Lee 2013). b) Clipping adjusts contrasts so that they cannot fall below the CSF at each spatial frequency ( $\alpha$, SUBTHRESHOLD), or above the saturation threshold ( $\beta$, SATURATED). 
Subthreshold contrasts are subtracted, and signals at each spatial frequency are multiplied by a gain value - denoted by arrow length in (c) - so that on average natural images have equal power at each spatial frequency (whitening). The saturation threshold is calculated from the CSF and channel bandwidth, $\varepsilon$ (4 in this example) at each spatial frequency. High and low spatial frequency channels therefore have low contrast sensitivity, but encode a large range of image contrasts, whereas intermediate spatial frequencies have high sensitivity and a low dynamic range. To demonstrate the clipping effects, we show an input image with sinewaves of different spatial frequencies and contrasts (d). (e) shows bandpass spatial filters and (f) highlights regions that are clipped or preserved. The overlap between neighbouring octaves (f) means that where contrasts are saturated for one channel, they are unlikely to be saturated for all neighbouring channels so that contrast differences are detectable even in high contrast scenes. Note that the fine lines in these illustrative images suffer from moiré effects when viewed on a monitor.

\section{Estimation of the bandwidth, $\varepsilon$}

Channel bandwidth $(\varepsilon)$ is estimated by fitting the model to human psychophysical data from Whittle's (Whittle 1992) investigation of the crispening effect. This study described how perceived lightness varies with luminance, and how contrast sensitivity depends on contrast and background luminance, by asking subjects to adjust target luminances to make equal-interval brightness series (Figures 3a, 4a). We created images simulating the viewing conditions in Whittle's experiment, including the spatial arrangement and luminance of the grey patches that he used to create perceptually uniform equal-contrast steps. Raw data (Figure 3a) were extracted from figures using WebPlotDigitiser (Rohatgi 2020). Based on least squares fitting, $\varepsilon$ is 15 for the circularly symmetrical version of the SBF model $\left(\mathrm{DoG}, \mathrm{R}^{2}=0.994\right)$, and 3.75 for the oriented version of the model (Gabor, $\left.\mathrm{R}^{2}=0.995\right)$. These bandwidths are within the range encoded by single neurones (Baddeley et al. 1997; Laughlin 1981). Critically, the model recreates the characteristic inflection point around the background grey value. Lowering the bandwidth, and thereby increasing the proportion of saturated channels, produces a more extreme crispening effect, which suggests that crispening is due to saturation rather than to loss of contrast sensitivity with increasing contrast between targets and the background (Figure 2), which is the usual interpretation of Fechner's law (Whittle 1992).

Interestingly, the model with $\varepsilon$ derived from Whittle's (1992) crispening data accurately predicts the responses of primate retinal ganglion cells to sinewave gratings (Derrington and Lennie 1984) (Figure 3b). The model fit $\left(\mathrm{R}^{2}=0.972\right)$ is better than the authors' own function $\left(\mathrm{R}^{2}=0.952\right)$. Both the psychophysical crispening effect and bottom-up neural responses suggest that at around $4 \mathrm{cpd}$ the saturation threshold for the human vision and macaque retinal ganglion cells $\left(\beta_{\varpi=4}\right)$ is approximately 0.2 . 
a)

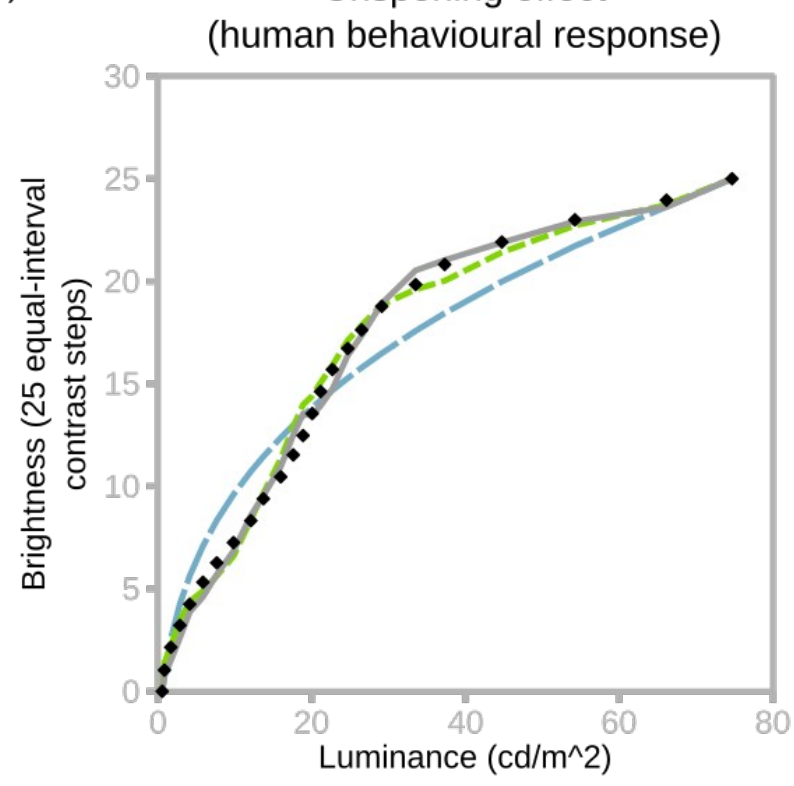

- Whittle 1992 data

- CIE "L" curve

---DoG Model

Gabor Model b) Sample macaque magnocellular ganglion response

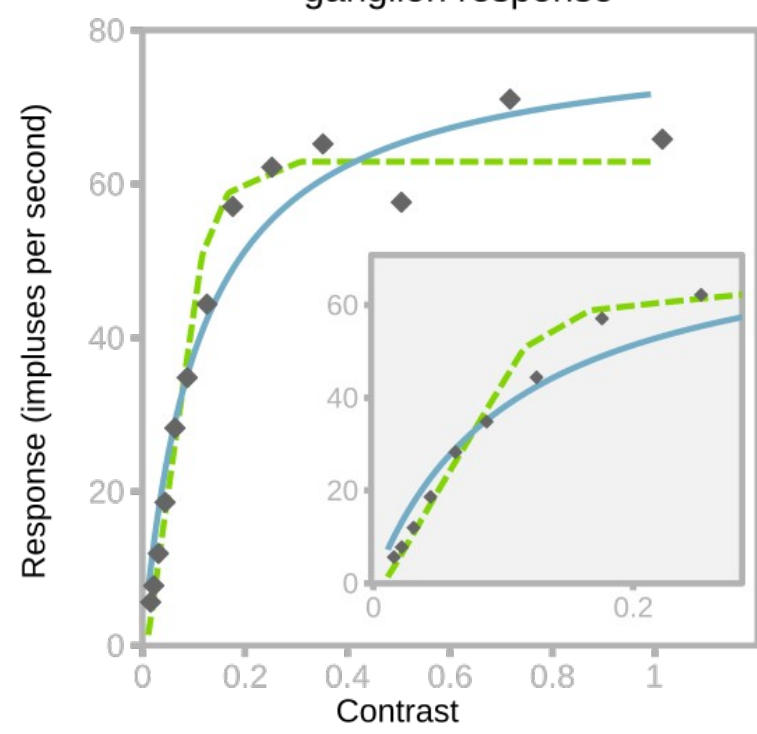

Derrington \& Lennie data

Derrington \& Lennie fit

$--=$ DoG Model $4 \mathrm{cpd}$ response

Figure 3. Fitting the SBL model to behavioural and neurophysiological data. a) fit to Whittle’s crispening data (1992, figure 9, "25/inc-dec/gray" treatment). Model output is scaled to the same $0-25$ range. The best-fitting bandwidth ( $\varepsilon$ ) for DoG filters is 15, and for Gabor (oriented) filters is 3.75, both of which result in a good fit to the raw data. The CIE $\mathrm{L}^{*}$ fit specifies lightness in psychophysics and does not account for contrast (Commision Internationale de l'Eclairage 1978). b) Model fit to single ganglion response data from Derrington and Lennie (1989, figure 11b). Fitting used a single free parameter that multiplied the arbitrary SBL model output to match neural firing responses (with zero intercept) by least-squares regression. The SBL model shows a linear contrast response and saturation point that provide a better fit than the authors' model. The inset excludes the three highest contrast values to highlight the linear relationship prior to saturation.

\section{Model Performance}

We tested the SBL model's ability to account for approximately thirty-seven perceptual phenomena that could plausibly be explained by low-level visual mechanisms (Adelson 2000; Shapiro and Todorovic 2016; Bertalmío et al. 2020), first for the version with oriented luminance filters, and secondarily for DoG filters (chromatic filters were always non-oriented, see above). Both versions of the model qualitatively predict almost all effects and, where relevant, their controls (Table 1, Figure 4 and Appendix). The only exceptions were the DoG (non-oriented) model's inability to predict illusory spots and bars in the Hermann grid and Poggendorff illusions, comparatively weak performance with one control for the Chevreul staircase, and the enhanced assimilation of colour created by bars in patterned chromatic backgrounds (Monnier and Shevell 2003). Nevertheless, this performance was achieved with no free parameters (Figures 1-3), and the model can be adjusted to predict all effects. 
bioRxiv preprint doi: https://doi org/10.1101/2022 $0222.481414 \cdot$ this version posted February 23,2022 . The copyright holder for this preprint (which was not certified by peer review) is the author/funder, who has granted bioRxiv a license to display the preprint in perpetuity. It is made available under aCC-BY 4.0 International license.

Key Predicts effect and relevant controls

Partially predicts effect, or does not predict controls

\begin{tabular}{|c|c|}
\hline Phenomenon & 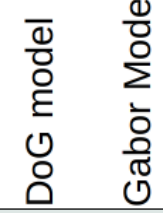 \\
\hline \multicolumn{2}{|l|}{ Crispening effect } \\
\hline \multicolumn{2}{|l|}{ Contrast sensitivity } \\
\hline \multicolumn{2}{|l|}{$\begin{array}{l}\text { Brightness } \\
\text { induction/assimilation (e.g. } \\
\text { White illusions) }\end{array}$} \\
\hline \multicolumn{2}{|l|}{$\begin{array}{l}\text { Simultaneous brightness } \\
\text { contrast }\end{array}$} \\
\hline \multicolumn{2}{|l|}{$\begin{array}{l}\text { lllusory bars and spots (e.g. } \\
\text { Hermann grid, Poggendorff } \\
\text { illusion) }\end{array}$} \\
\hline \multicolumn{2}{|l|}{$\begin{array}{l}\text { Contrast induction for spatial } \\
\text { frequency, orientation, and } \\
\text { chromatic contrast }\end{array}$} \\
\hline \multicolumn{2}{|l|}{$\begin{array}{l}\text { Colour constancy/chromatic } \\
\text { adaptation }\end{array}$} \\
\hline \multicolumn{2}{|l|}{$\begin{array}{l}\text { Chromatic simultaneous } \\
\text { contrast }\end{array}$} \\
\hline Chromatic assimilation & \\
\hline
\end{tabular}

207 Table 1. Summary of phenomena tested with oriented and non-oriented versions of the SBL model, with the

208 parameters, $\alpha, \beta$ and $\varepsilon$ fixed as explained in the text. All phenomena were qualitatively explained to some degree. For

209 illustrations of specific effects see the supplementary appendix. 
bioRxiv preprint doi: https://doi.org/10.1101/2022.02.22.481414; this version posted February 23, 2022. The copyright holder for this

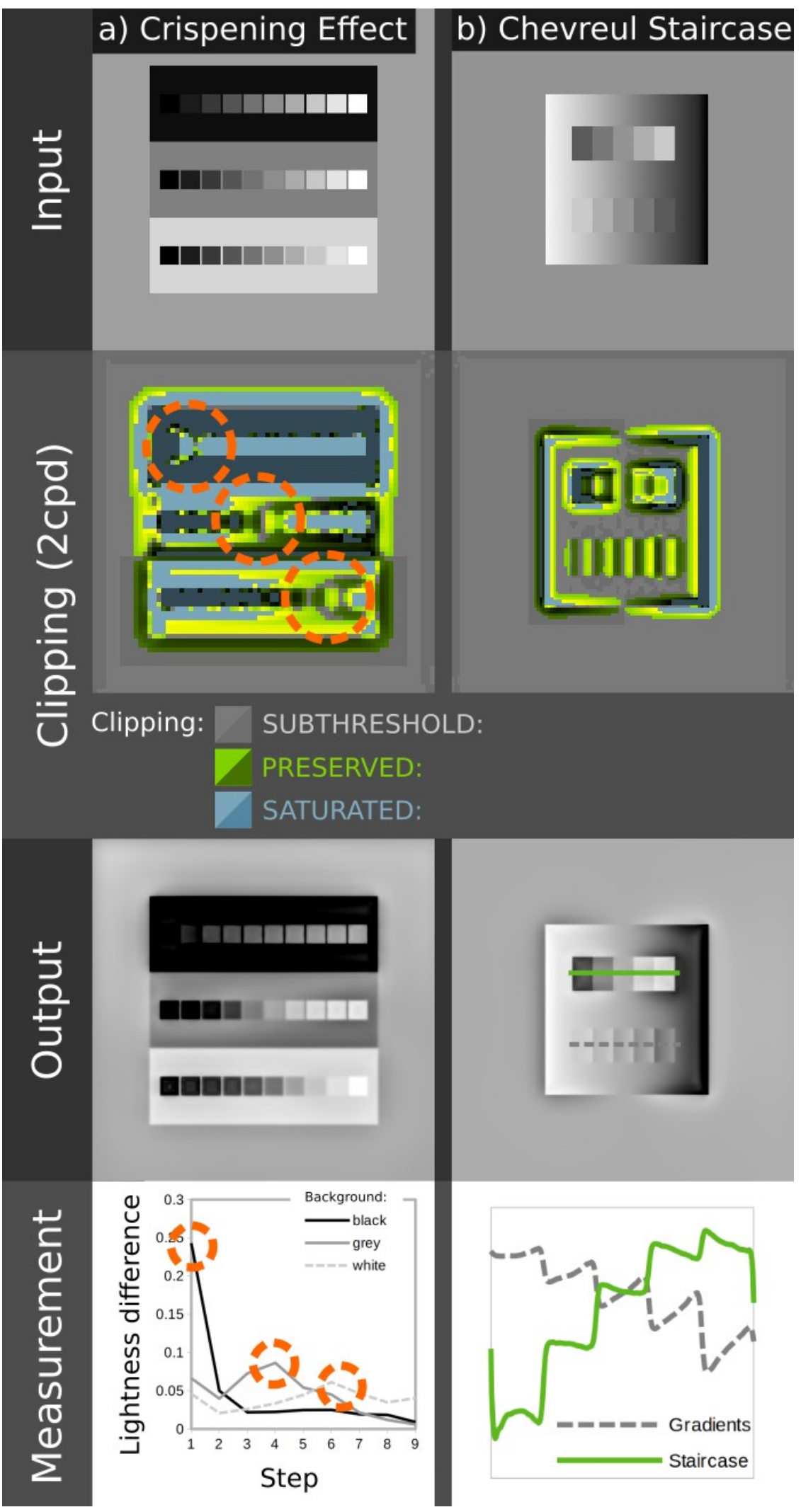

Figure 4. Illustration of dynamic range clipping by the SBL model. (a) for the crispening effect (Whittle 1992). The three rows of grey levels are identical, with equal step sizes. Against the black background contrasts appear largest for darker squares, whereas the opposite is true for the white background. The SBL model explains this effect through saturation; contrasts near the grey level of the local surroundings are preserved (highlighted with circles), while other contrasts are saturated (blue areas adjacent to the highlighted areas). The graph at the bottom plots differences between squares in the three rows, showing higher contrasts for dark, middle and light ranges respectively. Illusions such as the 
Chevreul staircase (b) are also explained in part by clipping. The upper staircase appears to be a series of square steps in grey level. The lower staircase has the same grey levels, but is flipped so that its gradient matches the surround gradient. The SBL model correctly predicts that the upper staircase is seen as square steps in grey level (solid green line) while the lower staircase is a series of gradients (dashed grey line). The plot shows pixel values in arbitrary units measured along each staircase, as highlighted in the output image. The model shows that this effect arises partly because the matched gradients of the lower staircase causes local subthreshold contrasts, and because contrasts are not balanced on each side of the step.

\section{Discussion}

The Spatiochromatic Bandwidth Limited model of colour appearance described here at least qualitatively predicts the appearance of a wide variety of images that are used to demonstrate colour and lightness perception (Table 1, Figure 4, Appendix). These include 'illusions' that have been explained by high-level interpretations of 3D geometry, lighting, atmospherics, or mid-level principles of perceptual organisation (Adelson 1993; Gilchrist 2014): for example White-Munker, shadow, Koffka ring and haze illusions. It is therefore parsimonious to suggest that many aspects of object appearance can be attributed to mechanisms adapted for - or consistent with - coding efficiency (Barlow 1961). Other accounts of the same phenomena invoke specialised mechanisms (e.g. Land and McCann 1971; Blakeslee and McCourt 2004) or top-down effects, which imply that multiple sources of sensory evidence and prior knowledge are used to infer the most likely cause of the stimulus (Brown and MacLeod 1997; Gregory 1997; Yuille and Kersten 2006; Adelson 2000). Neither does the SBL model invoke light adaptation or eye movements, which implies that colour constancy is largely independent of the adaptation state of the photoreceptors - provided that they are not saturated. By comparison the models used by standard colour spaces, such as CIE LAB/CIE CAM implement the von Kries co-efficient rule (Foster 2011), which assumes that photoreceptor responses are adapted to the global mean for a scene, even though chromatic adaptation is affected by both local and global colour contrasts (Kraft and Brainard 1999). Retinex (Land and McCann 1971) and Hunt models do normalise receptor signals to their local value (Hunt 2005a) but the weightings of global and local factors are poorly understood and the underlying mechanism is unclear (Kraft and Brainard 1999). Moreover, the adjustments required for colour constancy are largely complete within about 25ms (Rinner and Gegenfurtner 2000), which is too fast for receptor adaptation, but consistent with the purely feed-forward character of the SBL model. Figure 5 shows how the SBL model can account for colour appearance in a naturalistic image under variable illumination. More generally, the feed-forward architecture of the SBL model explains why many other visual phenomena appear without any delay, whereas existing models require feedback loops for normalisation (Land and McCann 1971; Hunt 2005a; Blakeslee and McCourt 2004). Thus, Brown and MacLeod (Brown and MacLeod 1997) comment that the distribution of surround 
colours affects colour appearance almost immediately, leaving little time for feedback or adaptation. Likewise, as suggested by (Chubb, Sperling, and Solomon 1989), contrast induction is explained without requiring the feedback invoked by (Nassi, Lomber, and Born 2013). This is because, according to the SBL model, low contrast surrounds allow all spatial bands to operate within their dynamic ranges, whereas high contrast surrounds saturate some spatial bands, resulting in underestimates of brightness contrast or chromaticity (Figures 3a, 4). The model also reconciles contrast constancy with a visual system that varies dramatically in contrast sensitivity and contrast gain across spatial frequencies, allowing suprathreshold contrasts to have a similar appearance at different distances (Georgeson and Sullivan 1975). Contrasts are predicted to be most constant where they are saturated across multiple spatial frequencies, e.g. where the blue regions in Figure $2 \mathrm{f}$ overlap. Pooling across spatial scales might explain the Abney effect, which is a shift in hue that occurs when white light is added to a monochromatic stimulus (Burns et al. 1984), because the colour stimulus may be below-threshold at some spatial bands, but above threshold for others, but we require specific data to estimate the bandwidth of chromatic channels (equivalent to Whittle's (1992) luminance crispening data). As noted above (Model, Figures 1, 2a), we assume that the bandwidth of the red-green signal equals the luminance DoG signal, but the blue-yellow signal has reduced the bandwidth, which produces plausible results when processing natural scenes, but future work should measure the chromatic bandwidth functions and determine whether the SBL model can account for the Abney effect quantitatively. Further developments of the chromatic SBL model should also investigate whether performance could be improved by modelling both single-opponent and double-opponent pathways. The latter are sensitive to both spatial frequency and orientation, and has been suggested to play a role in suprathreshold colour appearance (Shapley, Nunez, and Gordon 2019). However, we were able to simulate the same spatial-frequency/saturation effects with the non-oriented version of the SBL model (Appendix). 
bioRxiv preprint doi: https://doi.org/10.1101/2022.02 22 481414 ${ }^{\cdot}$ this version posted February 23, 2022. The copyright holder for this preprint (which was not certified by peer review) is the author/funder, who has granted bioRxiv a license to display the preprint in perpetuity. It is made available under aCC-BY 4.0 International license.
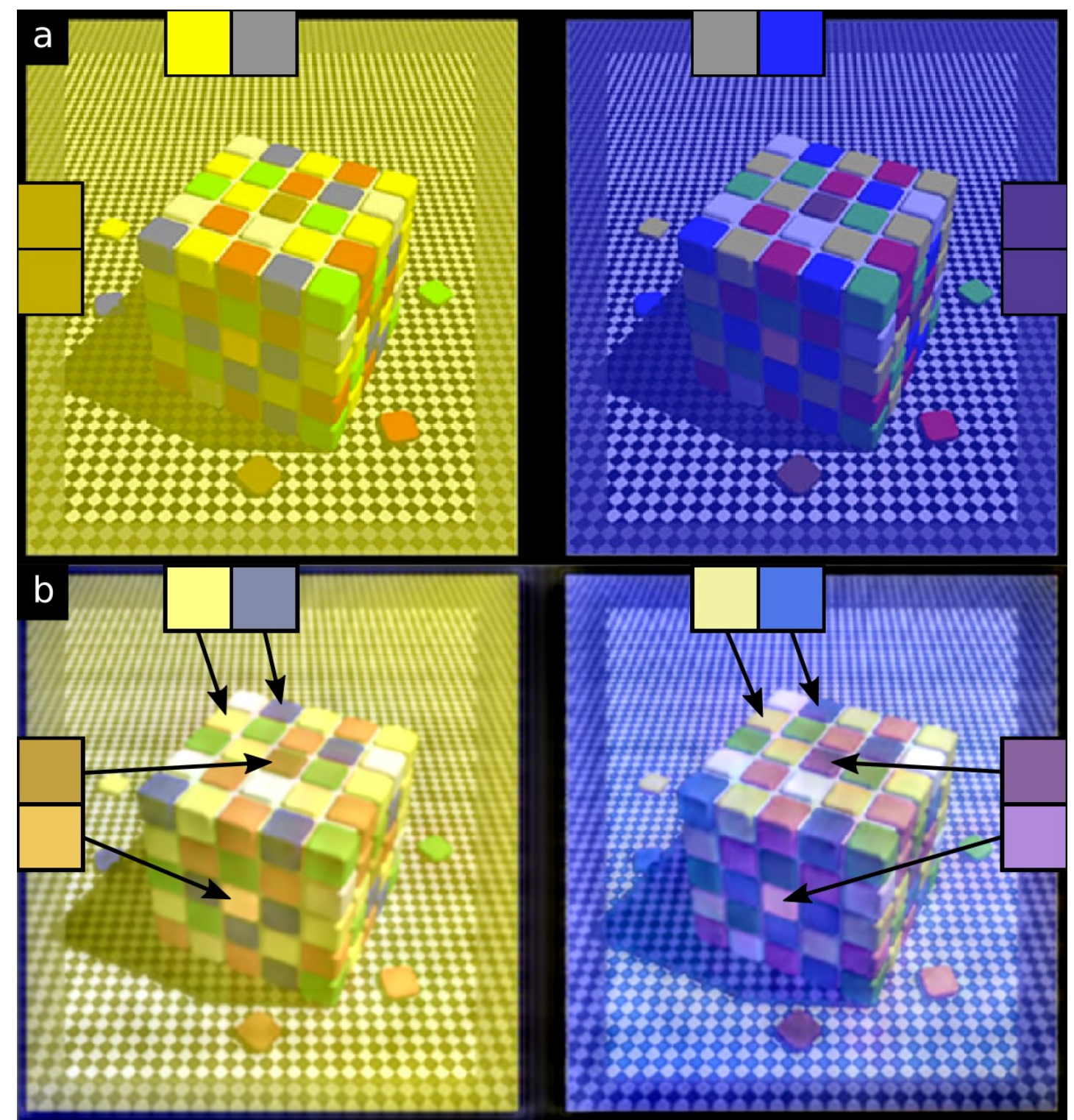

Figure 5. The SBL model can account for colour appearance in complex naturalistic images. (a) shows the input image (from Purves, Lotto, and Nundy 2002/Wikimedia) where the blue squares on the yellow-tinted side (left) and the yellow squares on the blue-tinted side (right) are physically the same grey (colours are shown in the squares at the top of the image). The SBL model (b) correctly predicts that the squares under both tinting regimes appear yellow and blue, rather than grey. The SBL model also predicts the powerful simultaneous contrast (or shadow) illusion present in this image whereby; the central tiles on top of the cube appear to be darker than the central tiles on the shaded side of the cube (colours shown in squares on the far left and for right hand sides).

\section{The Circularly Symmetric Version of the SBL Model and Animal Vision}

Whereas the oriented version of the SBL model uses orientation selective achromatic filters and circularly symmetrical chromatic filters (see above), the circularly symmetrical version uses DoG filters for all channels. For the visual phenomena that we have tested the oriented version of the SBL model predicts lightness and colour at least as well as the circularly symmetrical version (table 1). It might therefore seem logical to consider only the former, but visual systems of all animals probably have circularly symmetrical receptive fields [e.g. (Srinivasan et al. 1982)], but there is 
limited evidence for orientation selective cells other than in mammalian visual cortex. Also, the differences between the two versions of the SBL model seem to us to be surprisingly small. For example, both predict White effects, which might be expected to depend on orientation selective mechanisms (supplementary appendix; Blakeslee and McCourt 2004; Bertalmío et al. 2020), but only the oriented model correctly predicts the presence of illusory spots in the Hermann grid, and elimination of these spots in the wavy grid (Geier et al. 2008). Similarly, the oriented version of the model predicts Koffka rings and the Chevreul staircase (Figure 4b) more accurately than the circularly symmetrical version. The bandwidth, $\varepsilon$, for the non-oriented filter is approximately 15 , which matches neurophysiological measurements from primate retinal ganglion cells (Figure 3; Derrington and Lennie 1984). By comparison the bandwidth of the oriented version is estimated to be about four-fold lower than that of the non-oriented model, which is consistent with the low spike rates of neurons in the primary visual cortex (Baddeley et al. 1997). For a given spike rate partitioning the information into multiple channels allows a correspondingly reduced integration time.

The SBL model is useful for non-human animals because coding efficiency is a universal principle, and contrast sensitivity functions are known for many species [Figure 2a; (Caves and Johnsen 2018)], whereas psychophysical and neurophysiological data on visual mechanisms in non-primates is limited. Current research into non-human colour appearance typically uses the receptor noise limited (RNL) model (Vorobyev and Osorio 1998; Renoult, Kelber, and Schaefer 2017), which also assumes that early vision is constrained by low level noise. Others have sought to control for acuity and distance dependent effects (Caves and Johnsen 2018; Berg, Troscianko, et al. 2020; Barnett et al. 2018), but surprisingly few studies have utilised contrast sensitivity functions (Melin et al. 2016), and behavioural validation of the models is difficult (Silvasti, Valkonen, and Nokelainen 2021; Berg, Hollenkamp, et al. 2020). As with human vision, the SBL model may reconcile a number of key effects. For example, in a bird (blue tit, Cyanistes caeruleus) chromatic discrimination thresholds depended on the contrast of the surround (Silvasti, Valkonen, and Nokelainen 2021), which resembles chromatic contrast induction (Brown and MacLeod 1997) and is simulated by the SBL model. Shadow-illusion effects have also been demonstrated in fish (Simpson, Marshall, and Cheney 2016). Aside from predicting colour appearance the SBL model highlights comparatively unexplored trade-offs in visual systems, with contrast sensitivity potentially linked to dynamic range and to other factors such as low-light vision and temporal acuity. For example, birds have poor luminance contrast sensitivity, but high temporal acuity consistent with a low neural bandwidth in the SBL model (Potier, Mitkus, and Kelber 2018; Ghim and Hodos 2006; Boström et al. 2016). 
bioRxiv preprint doi: https://doi.org/10.1101/2022.02.22.481414; this version posted February 23, 2022. The copyright holder for this preprint (which was not certified by peer review) is the author/funder, who has granted bioRxiv a license to display the preprint in perpetuity. It is made available under aCC-BY 4.0 International license.

\section{Acknowledgements:}

We thank Jenny Bosten, Nick Scott-Samuel and Roland Baddeley for their constructive feedback.

\section{Funding:}

JT was funded by a NERC IRF (NE/P018084/1)

\section{Contributions}

JT conceived and developed the initial model, and performed the coding and testing; DO contributed to further model development and testing. Both authors wrote the manuscript.

\section{Competing Interest Statement}

We have no competing interests.

\section{References}

Adelson, Edward H. 1993. 'Perceptual Organization and the Judgment of Brightness'. Science 262 (5142): 2042-44.

. 2000. 'Lightness Perception and Lightness Illusions'. In The New Cognitive Neurosciences, 2nd ed. MIT Press, Cambridge, MA.

Atick, Joseph J., and A. Norman Redlich. 1992. 'What Does the Retina Know about Natural Scenes?’ Neural Computation 4 (2): 196-210.

Baddeley, Roland, L. F. Abbott, Michael C. A. Booth, Frank Sengpiel, Tobe Freeman, Edward A. Wakeman, and Edmund T. Rolls. 1997. 'Responses of Neurons in Primary and Inferior Temporal Visual Cortices to Natural Scenes'. Proceedings of the Royal Society of London. Series B: Biological Sciences 264 (1389): 1775-83. https://doi.org/10.1098/rspb.1997.0246.

Barlow, Horace B. 1961. 'Possible Principles Underlying the Transformation of Sensory Messages'. Sensory Communication 1 (01).

Barnett, James B., Constantine Michalis, Nicholas E. Scott-Samuel, and Innes C. Cuthill. 2018. 'Distance-Dependent Defensive Coloration in the Poison Frog Dendrobates Tinctorius, Dendrobatidae'. Proceedings of the National Academy of Sciences, May, 201800826. https://doi.org/10.1073/pnas.1800826115.

Berg, Cedric P. van den, Michelle Hollenkamp, Laurie J. Mitchell, Erin J. Watson, Naomi F. Green, N. Justin Marshall, and Karen L. Cheney. 2020. 'More than Noise: Context-Dependent Luminance Contrast Discrimination in a Coral Reef Fish (Rhinecanthus Aculeatus)'. Journal of Experimental Biology 223 (21). https://doi.org/10.1242/jeb.232090.

Berg, Cedric P. van den, Jolyon Troscianko, John A. Endler, N. Justin Marshall, and Karen L. Cheney. 2020. 'Quantitative Colour Pattern Analysis (QCPA): A Comprehensive Framework for the Analysis of Colour Patterns in Nature'. Methods in Ecology and Evolution 11 (2): 316-32. https://doi.org/10.1111/2041-210X.13328.

Bertalmío, Marcelo, Luca Calatroni, Valentina Franceschi, Benedetta Franceschiello, Alexander Gomez Villa, and Dario Prandi. 2020. 'Visual Illusions via Neural Dynamics: WilsonCowan-Type Models and the Efficient Representation Principle'. Journal of Neurophysiology 123 (5): 1606-18. https://doi.org/10.1152/jn.00488.2019.

Blakeslee, Barbara, and Mark E. McCourt. 2004. 'A Unified Theory of Brightness Contrast and Assimilation Incorporating Oriented Multiscale Spatial Filtering and Contrast 
bioRxiv preprint doi: https://doi.org/10.1101/2022.02.22.481414; this version posted February 23, 2022. The copyright holder for this preprint (which was not certified by peer review) is the author/funder, who has granted bioRxiv a license to display the preprint in perpetuity. It is made available under aCC-BY 4.0 International license.
Normalization'.
Vision
Research
44
(21):
2483-2503.

https://doi.org/10.1016/j.visres.2004.05.015.

Bloj, Marina G., Daniel Kersten, and Anya C. Hurlbert. 1999. 'Perception of Three-Dimensional Shape Influences Colour Perception through Mutual Illumination’. Nature 402 (6764): 87779.

Bossomaier, Terry, and Allan W. Snyder. 1986. 'Why Spatial Frequency Processing in the Visual Cortex?’ Vision Research 26 (8): 1307-9.

Boström, Jannika E., Marina Dimitrova, Cindy Canton, Olle Håstad, Anna Qvarnström, and Anders Ödeen. 2016. 'Ultra-Rapid Vision in Birds'. PLoS ONE 11 (3). https://doi.org/10.1371/journal.pone.0151099.

Brainard, David H., and William T. Freeman. 1997. 'Bayesian Color Constancy'. JOSA A 14 (7): 1393-1411. https://doi.org/10.1364/JOSAA.14.001393.

Brown, Richard O., and Donald I. A. MacLeod. 1997. 'Color Appearance Depends on the Variance of Surround Colors'. Current Biology 7 (11): 844-49. https://doi.org/10.1016/S09609822(06)00372-1.

Burns, S. A., A. E. Elsner, J. Pokorny, and V. C. Smith. 1984. 'The Abney Effect: Chromaticity Coordinates of Unique and Other Constant Hues'. Vision Research 24 (5): 479-89. https://doi.org/10.1016/0042-6989(84)90045-2.

Carandini, Matteo, and David J. Heeger. 2012. 'Normalization as a Canonical Neural Computation'. Nature Reviews Neuroscience 13 (1): 51-62.

Caves, Eleanor M., and Sönke Johnsen. 2018. 'AcuityView: An r Package for Portraying the Effects of Visual Acuity on Scenes Observed by an Animal'. Methods in Ecology and Evolution 9 (3): 793-97. https://doi.org/10.1111/2041-210X.12911.

Chubb, C., G. Sperling, and J. A. Solomon. 1989. 'Texture Interactions Determine Perceived Contrast'. Proceedings of the National Academy of Sciences 86 (23): 9631-35. https://doi.org/10.1073/pnas.86.23.9631.

Commision Internationale de l'Eclairage. 1978. 'Recommendations on Uniform Color Spaces, Color-Difference Equations, Psychometric Color Terms'. Paris: CIE.

Conway, Bevil R. 2001. 'Spatial Structure of Cone Inputs to Color Cells in Alert Macaque Primary Visual Cortex (V-1)’. Journal of Neuroscience 21 (8): 2768-83.

Daugman, John G. 1985. 'Uncertainty Relation for Resolution in Space, Spatial Frequency, and Orientation Optimized by Two-Dimensional Visual Cortical Filters’. JOSA A 2 (7): 1160-69.

Derrington, A M, and P Lennie. 1984. 'Spatial and Temporal Contrast Sensitivities of Neurones in Lateral Geniculate Nucleus of Macaque.’ The Journal of Physiology 357 (December): 21940.

Enroth-Cugell, Christina, and John G. Robson. 1966. 'The Contrast Sensitivity of Retinal Ganglion Cells of the Cat'. The Journal of Physiology 187 (3): 517-52.

Fairchild, Mark D. 2013. Color Appearance Models. John Wiley \& Sons.

Field, David J. 1987. 'Relations between the Statistics of Natural Images and the Response Properties of Cortical Cells'. Josa a 4 (12): 2379-94.

Foster, D.H. 2011. 'Color Constancy'. Vision Research 51 (7): 674-700.

Geier, János, László Bernáth, Mariann Hudák, and László Séra. 2008. 'Straightness as the Main Factor of the Hermann Grid Illusion'. Perception 37 (5): 651-65. https://doi.org/10.1068/p5622.

Georgeson, M A, and G D Sullivan. 1975. 'Contrast Constancy: Deblurring in Human Vision by Spatial Frequency Channels.’ The Journal of Physiology 252 (3): 627-56.

Ghim, Mimi M., and William Hodos. 2006. 'Spatial Contrast Sensitivity of Birds'. Journal of Comparative Physiology A 192 (5): 523-34. https://doi.org/10.1007/s00359-005-0090-5.

Gilchrist, Alan. 2014. 'A Gestalt Account of Lightness Illusions'. Perception 43 (9): 881-95. https://doi.org/10.1068/p7751.

Gregory, Richard L. 1997. 'Knowledge in Perception and Illusion'. Philosophical Transactions of the Royal Society of London. Series B: Biological Sciences 352 (1358): 1121-27. 
Hunt, Robert William Gainer. 2005a. The Reproduction of Colour. John Wiley \& Sons.

. 2005b. The Reproduction of Colour. John Wiley \& Sons.

Judd, Deane B. 1940. 'Hue Saturation and Lightness of Surface Colors with Chromatic Illumination'. JOSA 30 (1): 2-32. https://doi.org/10.1364/JOSA.30.000002.

Kane, David, and Marcelo Bertalmío. 2019. 'A Reevaluation of Whittle $(1986,1992)$ Reveals the Link between Detection Thresholds, Discrimination Thresholds, and Brightness Perception'. Journal of Vision 19 (1): 16-16. https://doi.org/10.1167/19.1.16.

Kim, Kil Joong, Rafal Mantiuk, and Kyoung Ho Lee. 2013. 'Measurements of Achromatic and Chromatic Contrast Sensitivity Functions for an Extended Range of Adaptation Luminance'. In Human Vision and Electronic Imaging XVIII, 8651:86511A. International Society for Optics and Photonics.

Kraft, J. M., and D. H. Brainard. 1999. 'Mechanisms of Color Constancy under Nearly Natural Viewing'. Proceedings of the National Academy of Sciences 96 (1): 307-12. https://doi.org/10.1073/pnas.96.1.307.

Kulikowski, J. J. 1976. 'Effective Contrast Constancy and Linearity of Contrast Sensation'. Vision Research 16 (12): 1419-31.

Land, Edwin H., and John J. McCann. 1971. 'Lightness and Retinex Theory'. JOSA 61 (1): 1-11. https://doi.org/10.1364/JOSA.61.000001.

Land, Edwin H. and others. 1977. The Retinex Theory of Color Vision. Scientific America. http://xa.yimg.com/kq/groups/18365325/470399326/name/E.Land_-_Retinex_Theory \%25255B1\%25255D.pdf.

Laughlin, Simon. 1981. 'A Simple Coding Procedure Enhances a Neuron’s Information Capacity'. Zeitschrift Für Naturforschung C 36 (9-10): 910-12. https://doi.org/10.1515/znc-1981-91040.

Marĉelja, S. 1980. 'Mathematical Description of the Responses of Simple Cortical Cells'. JOSA 70 (11): $1297-1300$.

Melin, Amanda D., Donald W. Kline, Chihiro Hiramatsu, and Tim Caro. 2016. 'Zebra Stripes through the Eyes of Their Predators, Zebras, and Humans’. PLOS ONE 11 (1): e0145679. https://doi.org/10.1371/journal.pone.0145679.

Monnier, Patrick, and Steven K. Shevell. 2003. 'Large Shifts in Color Appearance from Patterned Chromatic Backgrounds'. Nature Neuroscience 6 (8): 801-2. https://doi.org/10.1038/nn1099.

Mullen, K. T. 1985. 'The Contrast Sensitivity of Human Colour Vision to Red-Green and BlueYellow Chromatic Gratings.' The Journal of Physiology 359 (1): 381-400. https://doi.org/10.1113/jphysiol.1985.sp015591.

Nassi, Jonathan J., Stephen G. Lomber, and Richard T. Born. 2013. 'Corticocortical Feedback Contributes to Surround Suppression in V1 of the Alert Primate'. Journal of Neuroscience 33 (19): 8504-17. https://doi.org/10.1523/JNEUROSCI.5124-12.2013.

Potier, Simon, Mindaugas Mitkus, and Almut Kelber. 2018. 'High Resolution of Colour Vision, but Low Contrast Sensitivity in a Diurnal Raptor'. Proceedings of the Royal Society B 285 (1885): 20181036.

Ratliff, Floyd. 1965. Mach Bands: Quantitative Studies on Neural Networks. San Francisco, CA: Holden-Day.

Renoult, Julien P., Almut Kelber, and H. Martin Schaefer. 2017. 'Colour Spaces in Ecology and Evolutionary Biology’. Biological Reviews $92 \quad$ (1): 292-315. https://doi.org/10.1111/brv.12230.

Rinner, Oliver, and Karl R. Gegenfurtner. 2000. 'Time Course of Chromatic Adaptation for Color Appearance and Discrimination'. Vision Research 40 (14): 1813-26.

Roe, Anna W., Leonardo Chelazzi, Charles E. Connor, Bevil R. Conway, Ichiro Fujita, Jack L. Gallant, Haidong Lu, and Wim Vanduffel. 2012. 'Toward a Unified Theory of Visual Area V4'. Neuron 74 (1): 12-29. https://doi.org/10.1016/j.neuron.2012.03.011.

Rohatgi, Ankit. 2020. 'WebPlotDigitizer: Version 4.4'. https://automeris.io/WebPlotDigitizer. 
Ruderman, Daniel L., Thomas W. Cronin, and Chuan-Chin Chiao. 1998. 'Statistics of Cone Responses to Natural Images: Implications for Visual Coding’. JOSA A 15 (8): 2036-45.

Schneider, Caroline A., Wayne S. Rasband, and Kevin W. Eliceiri. 2012. 'NIH Image to ImageJ: 25 Years of Image Analysis'. Nat Methods 9 (7): 671-75.

Shapiro, Arthur G., and Dejan Todorovic. 2016. The Oxford Compendium of Visual Illusions. Oxford University Press.

Shapley, Robert, Valerie Nunez, and James Gordon. 2019. 'Cortical Double-Opponent Cells and Human Color Perception’. Current Opinion in Behavioral Sciences, Visual perception, 30 (December): 1-7. https://doi.org/10.1016/j.cobeha.2019.04.001.

Silvasti, Sanni A., Janne K. Valkonen, and Ossi Nokelainen. 2021. 'Behavioural Thresholds of Blue Tit Colour Vision and the Effect of Background Chromatic Complexity'. Vision Research 182 (May): 46-57. https://doi.org/10.1016/j.visres.2020.11.013.

Simoncelli, Eero P., and Bruno A. Olshausen. 2001. 'Natural Image Statistics and Neural Representation’. Annual Review of Neuroscience 24 (1): 1193-1216.

Simpson, Elisha E., N. Justin Marshall, and Karen L. Cheney. 2016. 'Coral Reef Fish Perceive

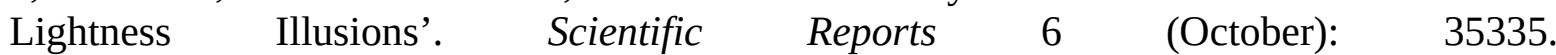
https://doi.org/10.1038/srep35335.

Solomon, Samuel G., and Peter Lennie. 2007. 'The Machinery of Colour Vision'. Nature Reviews Neuroscience 8 (4): 276-86.

Srinivasan, Mandyam Veerambudi, Simon Barry Laughlin, A. Dubs, and George Adrian Horridge. 1982. 'Predictive Coding: A Fresh View of Inhibition in the Retina'. Proceedings of the Royal Society of London. Series B. Biological Sciences 216 (1205): 427-59. https://doi.org/10.1098/rspb.1982.0085.

Tadmor, Y., and D. J. Tolhurst. 2000. 'Calculating the Contrasts That Retinal Ganglion Cells and LGN Neurones Encounter in Natural Scenes'. Vision Research 40 (22): 3145-57.

Troscianko, Jolyon, and Martin Stevens. 2015. 'Image Calibration and Analysis Toolbox - a Free Software Suite for Objectively Measuring Reflectance, Colour and Pattern'. Methods in Ecology \& Evolution 6 (11): 1320-31. https://doi.org/10.1111/2041-210X.12439.

Vorobyev, Misha, and D. Osorio. 1998. 'Receptor Noise as a Determinant of Colour Thresholds'. Proceedings of the Royal Society of London. Series B: Biological Sciences 265 (1394): 35158.

Wandell, Brian A. 1995. 'Foundations of Vision Sinauer Associates'. Inc. Sunderland MA.

Watt, R. J., and M. J. Morgan. 1985. 'A Theory of the Primitive Spatial Code in Human Vision'. Vision Research 25 (11): 1661-74. https://doi.org/10.1016/0042-6989(85)90138-5.

White, Michael. 1979. 'A New Effect of Pattern on Perceived Lightness'. Perception 8 (4): 413-16.

Whittle, Paul. 1992. 'Brightness, Discriminability and the "Crispening Effect"'. Vision Research 32 (8): 1493-1507. https://doi.org/10.1016/0042-6989(92)90205-W.

Witzel, Christoph, Hanna Valkova, Thorsten Hansen, and Karl R. Gegenfurtner. 2011. 'Object Knowledge Modulates Colour Appearance'. I-Perception 2 (1): 13-49.

Yuille, Alan, and Daniel Kersten. 2006. 'Vision as Bayesian Inference: Analysis by Synthesis?' Trends in Cognitive Sciences 10 (7): 301-8.

\title{
Supplementary Material
}

\section{Description of the Spatiochromatic Bandwidth Limited model}

\author{
Model input Requirements:
}


- A linear cone-catch image of known angular width. For example, cone-catch images created by the micaToolbox (Troscianko \& Stevens 2015), or sRGB images converted to linear CIE XYZ channels. Our implementation accepts either sRGB images or cone catch images, and uses 32-bit images and processing throughout; 8-bits per channel is an insufficient dynamic range for coding linear natural scenes. The image should be scaled so that its resolution matches or exceeds the highest spatial frequency being modelled. For example, the DoG kernel we use has its peak wavelength sensitivity at 5.7 pixels, and the highest SF we model is $16 \mathrm{cpd}$, so the image should be scaled so that each degree of angular width has $16 \mathrm{x} 5.7$ pixels, i.e. 91.2 pixels per degree.

- Contrast sensitivity functions (CSFs) for the luminance and chromatic opponent channels (red-green and blue-yellow). Our code uses values from Kim et al. (2013). These values should be scaled so that contrasts are Michelson Contrast values - e.g. (red-green)/(red+green). Note that sensitivity is the inverse of the threshold contrast (i.e. higher sensitivity = lower threshold contrasts, Figure 2a).

- Bandwidth values $(\varepsilon)$ for luminance and each chromatic opponent channel (i.e. three values for human vision). These can be estimated from behavioural data (e.g. crispening effect, Figure 3a), or from neurophysiological data (Figure 3b). Suitable data are currently lacking for chromatic channel bandwidth, but we assume the red-green channel bandwidth equals that for the luminance channel, and the blue-yellow channel has about $30 \%$ of this bandwidth, in order to achieve efficient coding in natural scenes.

- Gain functions specify how each spatial frequency should be scaled following the clipping process. These are calculated by processing a library of images of natural scenes through the model with all gain values set to 1 (i.e. no gain), and measuring the resulting standard deviation of each channel. Normalising to these values gives output contrasts with standard deviations of 1 at each spatial frequency.

The values we used are supplied in the supplementary code.

Image Pre-Processing:

The cone catch image is converted to three channels: luminance, red-green opponency and blueyellow opponency. The luminance channel is the average of all cone catch values from each receptor class, weighted by their cone ratios:

$$
\operatorname{lum}=0.629 R+0.314 G+0.057 B
$$

Where R, G, and B are the longwave, mediumwave and shortwave cone catch pixel values respectively. Cone ratios here are from Hofer et al. (2005). 
The chromatic signals are calculated as Michelson contrasts:

$$
\text { RedGreen }=\frac{R-G}{R+G}
$$

\section{Spatial Filtering}

Each channel is convolved with either a Difference-of-Gaussian kernel or Gabor kernel. DoG kernels are orientation-insensitive, and are used for luminance and chromatic channels. Gabor kernels are orientation sensitive and are optionally used instead of DoG for the luminance channel. Our implementation uses conventional kernel functions (see code for exact parameters, examples shown in Figure 1b); for the DoG the surround has a sigma value 1.6 times larger than the centre, and for the Gabor filter we use 4 orientations (sigma $=2$, gamma $=1$, frequency $=3$ ). Our spatial filtering differs from that used previously in that we use Michelson Contrasts. Conventionally, the spatial filtering procedure uses logged input images and then applies a convolution. The result is mathematically identical to dividing the centre response by the surround. While this is computationally efficient, the resulting contrasts are non-linear and unbounded (e.g. values can easily go implausibly high), and cannot be reliably matched to the behaviour described in CSFs. The chromatic channels have already had the Michelson contrast function applied, so the convolution is equivalent to simulating Michelson contrasts based on red-centre versus greensurround, or yellow-centre versus blue-surround giving contrast values, $\varphi$. However, the Michelson contrast stage must be applied to the luminance channel following spatial filtering in order to compare centre and surround (or positive and negative regions in the Gabor kernel), i.e.:

$$
\varphi=m \frac{\text { centre }- \text { surround }}{\text { centre }+ \text { surround }}
$$

Our implementation achieves this by calculating both signed and unsigned (absolute) convolutions for the numerator and denominator respectively. $m$ is a parameter that scales the kernel's (arbitrary) amplitude to create contrasts that match the same scale as the contrast sensitivity functions. CSFs are generally calculated using sinewave gratings, so to calculate $m$ we first create an image with a sinewave spatial frequency that matches the kernel's peak sensitivity (5.7 pixels in our case). The sinewave amplitude is set to a known Michelson contrast of e.g. 0.1, and then is convolved with the kernel. $m$ is then the maximum contrast from the convolved image divided by the Michelson contrast of the input sinewave (i.e. 0.1). This simply scales the contrasts, $\varphi$, so that they are directly comparable to the conditions used to measure CSFs.

\section{Clipping}

The activation threshold, $\alpha$, is the inverse of contrast sensitivity, specified by the CSF at each spatial frequency, $\varpi$ (see Figure 2a for example CSFs): 


$$
\alpha_{\varpi}=\frac{1}{\text { ContrastSensitivity }_{\varpi}}
$$

Any contrasts below the saturation threshold are set to zero, while all other contrasts have the saturation threshold subtracted (Kulikowski 1976):

$$
\begin{gathered}
\text { If } \varphi<\alpha_{\varpi} \text { and } \varphi>0, \varphi_{\text {clipped }}=0 \\
\text { elseif } \varphi>0, \varphi_{\text {clipped }}=\varphi-\alpha_{\varpi}
\end{gathered}
$$

The sign is preserved for negative contrasts (i.e. the model assumes both centre-on and centre-off behaviour, described by positive or negative convolved pixel values respectively). However, in natural scenes the luminance DoG convolution results in negative contrasts that are twice as large as the positive ones (this does not apply to chromatic DoG or Gabor convolutions, where positive contrasts match negative contrasts). Following the principles of efficient coding we therefore assume that any centre-off channels are tuned to the same dynamic range, and multiply $\alpha$ by 2 i.e.:

$$
\begin{gathered}
\text { If } \varphi>-2 \alpha_{\varpi} \text { and } \varphi<0, \varphi_{\text {clipped }}=0 \\
\quad \text { elseif } \varphi<0, \varphi_{\text {clipped }}=\varphi+2 \alpha_{\varpi}
\end{gathered}
$$

Bandwidth, $\varepsilon$, is assumed to be uniform across all spatial frequencies, and this is used to calculate the saturation threshold, $\beta$, at each spatial frequency:

$$
\beta_{\omega}=\alpha_{\omega} \varepsilon
$$

The bandwidth can either be estimated by fitting the model to behavioural data (Figure 3a), or based on the dynamic range of single neurones (Figure 3b). Contrasts greater than the saturation threshold are set to equal the saturation threshold, creating a hard upper threshold. As above, negative contrasts are doubled for luminance DoG models (but not chromatic or Gabor models):

$$
\begin{gathered}
\text { If } \varphi>\beta_{\varpi}, \varphi_{\text {clipped }}=\beta_{\varpi} \\
\text { elseif } \varphi \leftarrow 2 \beta_{\varpi}, \varphi_{\text {clipped }}=2 \beta_{\varpi}
\end{gathered}
$$

This clipping process defines the dynamic range of the model at each spatial frequency. The result is that spatial frequencies with high contrast sensitivity also saturate much faster with increasing contrast, resulting in small dynamic range. Meanwhile spatial frequencies with low contrast sensitivity have a much larger dynamic range (Figure 2b). However, the overlap in sensitivity between adjacent spatial frequencies means that almost all contrasts are within the dynamic range of one or more spatial frequencies (the orange areas in Figure 2f), implying low bandwidths can be combined with high contrast sensitivity for efficient coding as long as there is a large range in dynamic ranges, and sufficient overlap in adjacent spatial frequencies. This explains why humans can perceive contrasts in natural scenes (or on high-definition televisions) over a dynamic range greater than 10,000:1, while our dynamic range for sinewaves is around 200:1. 


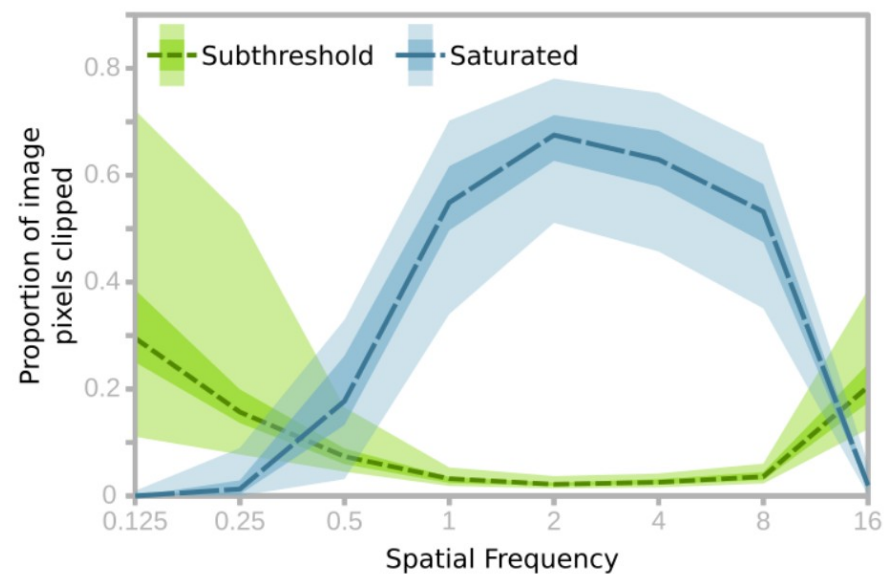

Supplementary Figure 1. Plot showing the proportion of pixels in each channel that are either saturated or subthreshold in typical natural scenes. The results are based on 34 images of natural scenes, dashed lines show the median value, shaded areas show the interquartile range and full range of the data. High contrast sensitivity at intermediate spatial frequencies causes substantially more saturation, while the lower sensitivity channels show substantial proportion of subthreshold contrasts.

\section{$\underline{\text { Gain }}$}

Following clipping, contrasts are multiplied so that each spatial frequency results in equal contribution to the contrasts in the pooled image. i.e. in natural scene statistics each spatial frequency should contain equal contrast/information (Field, 1987), however the clipping process substantially reduces the average amplitude of contrasts at intermediate spatial frequencies. The gain step equalises the average contrast amplitudes at each spatial frequency, i.e.:

$$
\Phi=\frac{\varphi_{\text {clipped }}}{\sigma_{\varpi}}
$$

Where $\sigma_{\varpi}$ is the standard deviation of all $\varphi_{\text {clipped }}$ values in an image of a natural scene filtered at spatial frequency $\omega$, resulting in gain-corrected contrasts, $\Phi$.

\section{Post-clipping smoothing}

The hard upper and lower clipping thresholds ( $\alpha$ and $\beta$ ) produce undesirable artefacts in the pooled image. We remove these by applying a Gaussian blur to each channel prior to pooling, with sigma values well below the filter's spatial frequency (e.g. sigma value below 1 pixel radius, where the kernel's peak wavelength sensitivity is 5.7 pixels). This step removes the artefacts, and the smoothing effect is responsible for the curvature near the saturation threshold shown in Figure 3b, matching the behaviour of primate ganglia (Derrington and Lennie, 1984). This stage mirrors the correlated firing of neighbouring retinal ganglion cells cells where on-centre cells excite neighbouring on-centre cells, and likewise for off-centre cells, while oncentre and off-centre cells inhibit one-another (Nelson 1995).

\section{Pooling}

Pooling simply sums the contrast at each pixel location across each spatial frequency: 


$$
\text { PooledOutput }=\sum_{\varpi_{\min }}^{\varpi_{\max }} \Phi
$$

429 This results in recombined luminance, red-green and blue-yellow chromatic channels. This output is

430 designed to match subjective colour appearance, and it is therefore not straightforward to present these

431 images on an sRGB display without confounding the very effects it seeks to predict. Nevertheless, we can

432 convert back to a space that roughly approximates the cone-catch input:

$$
\begin{aligned}
R_{\text {output }} & =\frac{2 \text { Lum }}{1+(1-\text { RedGreen }) /(1+\text { RedGeen })} \\
G_{\text {output }} & =\frac{R_{\text {output }}}{(1+\text { RedGreen }) /(1-\text { RedGeen })} \\
B_{\text {out put }} & =\text { Lum } \frac{1+(1-\text { BlueYellow })}{1+\text { BlueYellow }}-\text { Lum }
\end{aligned}
$$


bioRxiv preprint doi: https://doi.org/10.1101/2022.02.22.481414; this version posted February 23, 2022. The copyright holder for this preprint (which was not certified by peer review) is the author/funder, who has granted bioRxiv a license to display the preprint in perpetuity. It is made available under aCC-BY 4.0 International license.

Appendix to "A model of colour appearance based on efficient coding of natural images" by Jolyon Troscianko \& Daniel Osorio

Key

Predicts effect and relevant controls

Predicts effect, but not controls, or only partially predicts effect

Cannot not predict effect

Phenomenon

Phenomenon

Description

Source

DoG (non-oriented) Mode

Gabor (oriented) Mode

Crispening Effect The crispening effect causes perceived contrasts to be greater when the grey levels are nearer those of the background. The effect was modelled by Whittle (1992), and subsequent work suggests the dipper effect [Solomon, (2009)] and divisive gain explains the effect [Kane and Bertalmio (2019)]. Here we use Whittle's 1992 data to determine the dynamic range of human luminance vision.

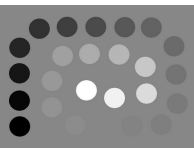
Human subjects adjusted grey targets in equal-contrast steps on a grey Generated DoG fit, DR=15, background from Whittle $\mathrm{R}^{2}=0.994$

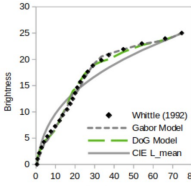
Gabor fit, Both models $R^{2}=0.995 \quad\left(R^{2}=0.944\right)$

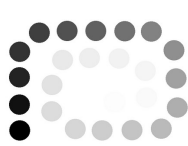

White background As above with white background

$\begin{array}{ll}\text { Generated } & \text { DoG fit when } \\ \text { from Whittle } & \text { using the above } \\ \text { (1992) data } & \mathrm{DR} \mathrm{R}^{2}=0.946\end{array}$

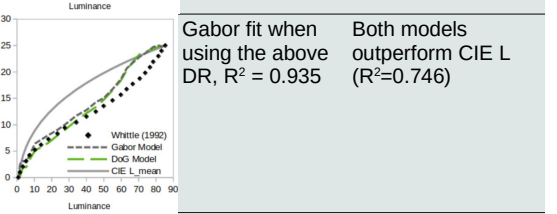

Contrast sensitivity The ability of humans and other animals to perceive contrasts is dependent on the spatial frequency of those contrasts. Contrast sensitivity functions describe the contrast a of a sinwave that is detectable at different spatial frequencies. A related phenomenon is contrast constancy, where suprathreshold contrasts appear to be uniform irrespective of spatial frequency.

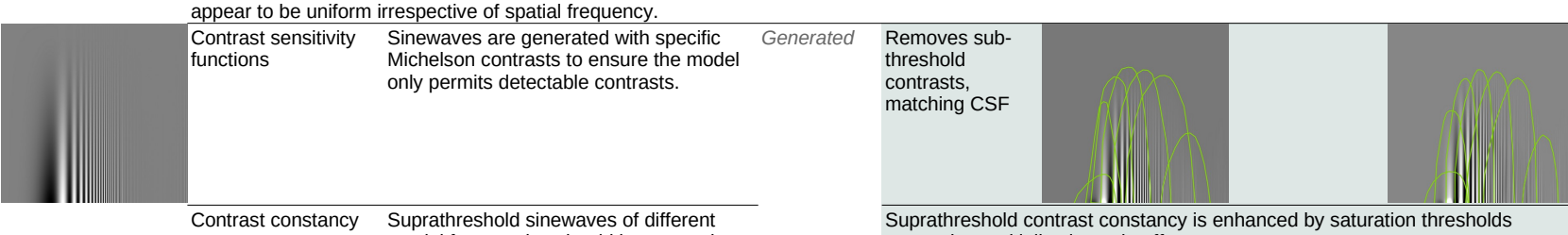

spatial frequencies should have equal

Suprathreshold contrast constancy is enhanced by saturation thresholds amplitudes.

preventing multiplicative gain effects.
Brightness illusions This family of illusions causes grey targets to differ in perceived brightness dependent on the arrangement of (typically high contrast) surrounds. Some of these illusions, such as simultaneous contrast and Mach bands have traditionally been attributed to centre-surround antagonism [Eagleman (2001)]. However the White illusions create the opposite effect, and have variously been attributed to oriented filtering with normalisation [Bertalmio et al. (2020), Blakeslee et al. (2016)], T-junctions [e.g. see Adelson (2000)], Gestalt/grouping/anchoring based mechanisms [Gilchrist (2014)]. A further set of illusions have been attributed to 3D surface and lighting based inferences [see Adelson (2000)], or atmospheric-based inferences [see Adelson (2000)]

\begin{tabular}{|c|c|c|}
\hline White's bars & $\begin{array}{l}\text { A grey bar flanked by black appears } \\
\text { darker than the same grey flanked by } \\
\text { white }\end{array}$ & $\begin{array}{l}\text { Adapted } \\
\text { from } \\
\text { Blakeslee \& } \\
\text { McCourt } \\
\text { (2004), and } \\
\text { Bertalmio et } \\
\text { al. (2020) }\end{array}$ \\
\hline
\end{tabular}

|||||||||
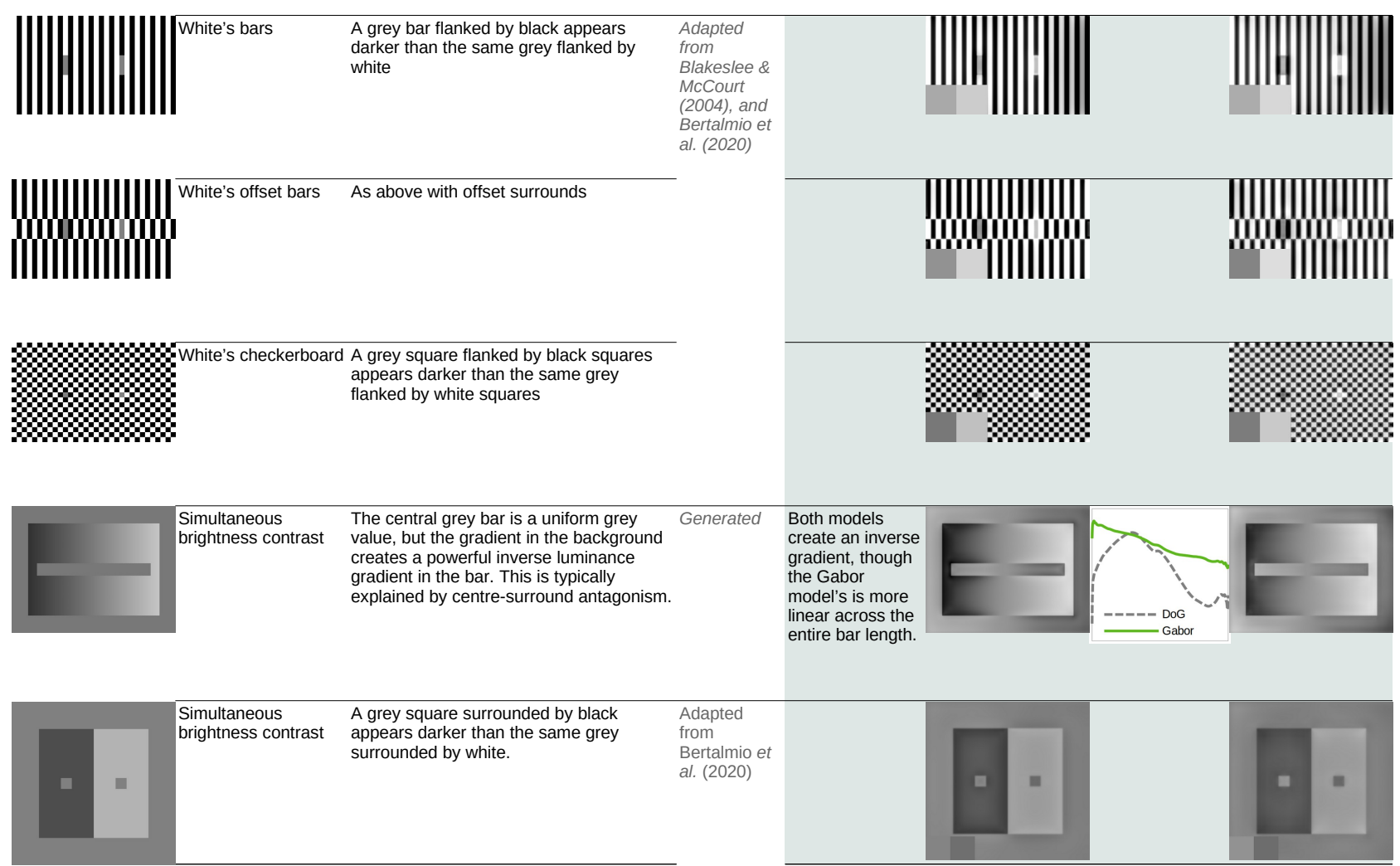
bioRxiv preprint doi: https://doi.org/10.1101/2022.02.22.481414; this version posted February 23, 2022. The copyright holder for this preprint (which was not certified by peer review) is the author/funder, who has granted bioRxiv a license to display the preprint in perpetuity. It is made available under aCC-BY 4.0 International license.




bioRxiv preprint doi: https://doi.org/10.1101/2022.02.22.481414; this version posted February 23, 2022. The copyright holder for this

preprint (which was not certified by peer review) is the author/funder, who has granted bioRxiv a license to display the preprint in perpetuity. It is made available under aCC-BY 4.0 International license.

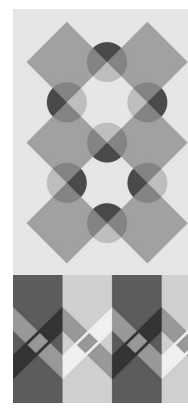

Haze illusion

Dark, high contrast surrounds increase perceived brightness of the lower tile. Adelson attributes the effect to perceived atmospheric differences between the tiles.

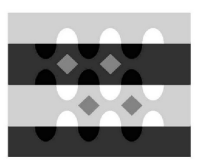

\section{Snake illusion}

Crisscross illusion

A patterned grey target surrounded by a light background appears darker than the same grey with dark surrounds. Note this is the opposite effect of White's illusions, and is similar to simultaneous contrast.
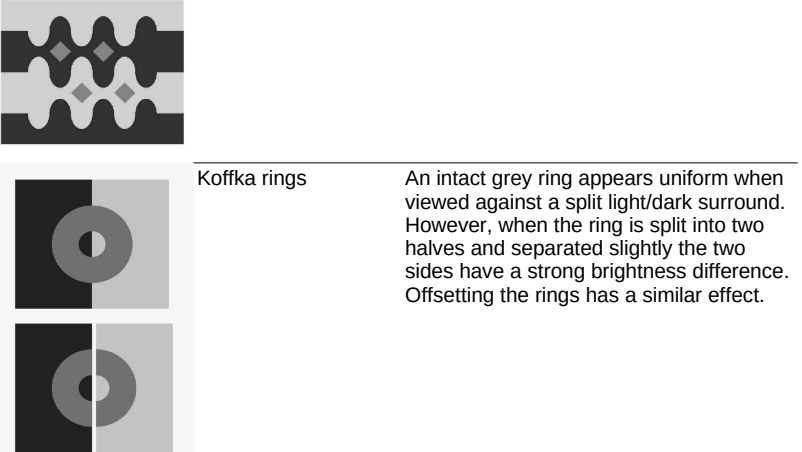

Similar to the crisscross illusion above, however a control shows how the effect can be negated by removing

"atmospheric" bands.

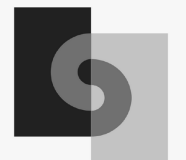

\section{Adelson checker}

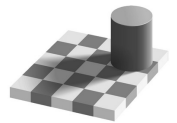

The shadow cast onto the checkerboard causes the shaded square to appear brighter than a square with the level outside of the shadow.

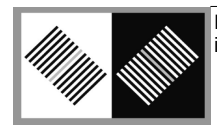

Reverse contrast illusion

The grey diagonal bar surrounded by background appears Gilchrist inverted example.

\section{Benary cross illusion The triangle cutting into the arm of the cross appears brighter than the triangle that spans between two arms.}
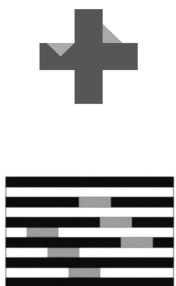

Wedding cake illusion Variant of White's bar illusion with zigzag background
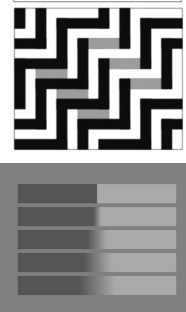

Mach bands are the perceived light and dark stripes created where a ramp of grey following $\begin{array}{ll}\text { meets a flat grey. Mach bands are } & \text { Kingdom } \\ \text { traditionally explained by centre-surround } & \text { (2014) }\end{array}$ traditionally explained by centre-surround antagonism, but other theories have been [see Kingdom (2014)].

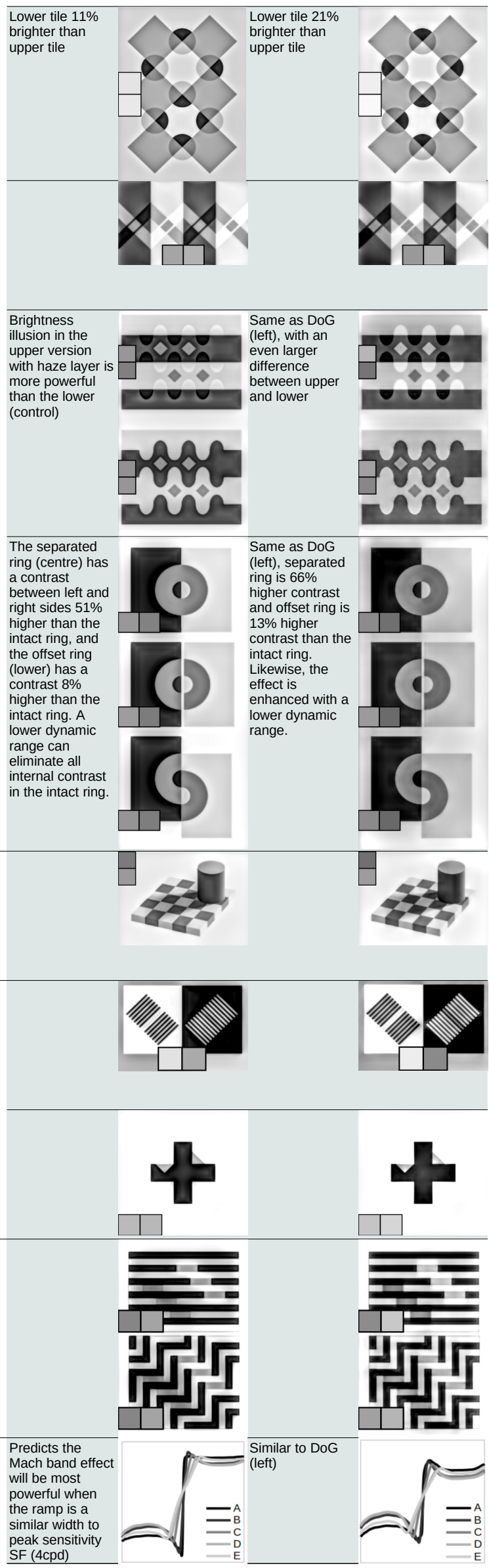


bioRxiv preprint doi: https://doi.org/10.1101/2022.02.22.481414; this version posted February 23, 2022. The copyright holder for this

preprint (which was not certified by peer review) is the author/funder, who has granted bioRxiv a license to display the preprint in perpetuity. It is made available under aCC-BY 4.0 International license.

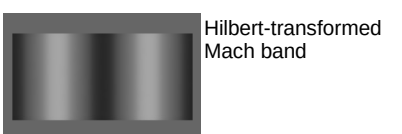

Various transforms have been shown to disrupt the Mach band effect, such as this Hilbert transform. These transforms generally simply remove the high spatial frequency "foot" of the Mach band.
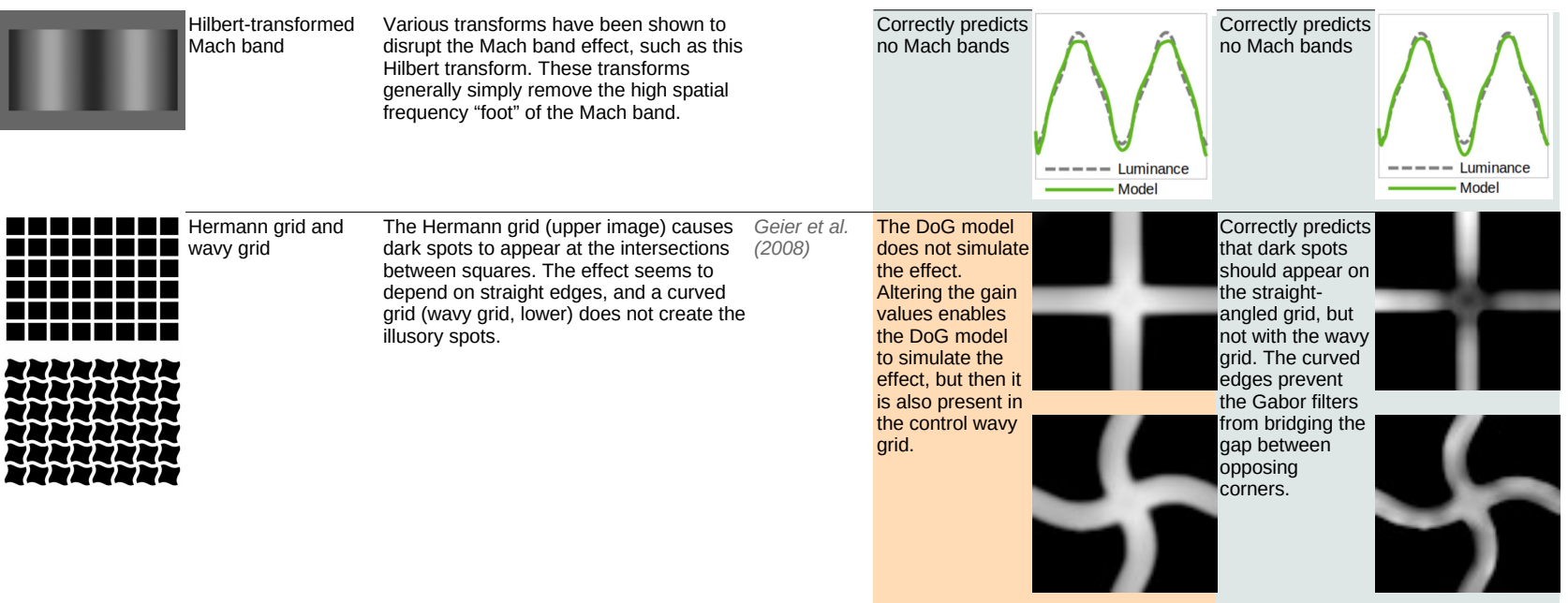

The Hermann grid (upper image) causes Geier et al. dark spots to appear at the intersections between squares. The effect seems to depend on straight edges, and a curved grid (wavy grid,
illusory spots.

Hermann grid and
wavy grid

.

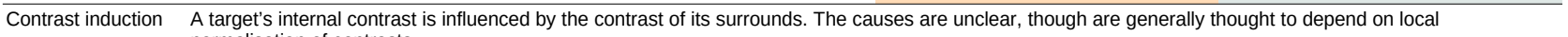
normalisation of contrasts.

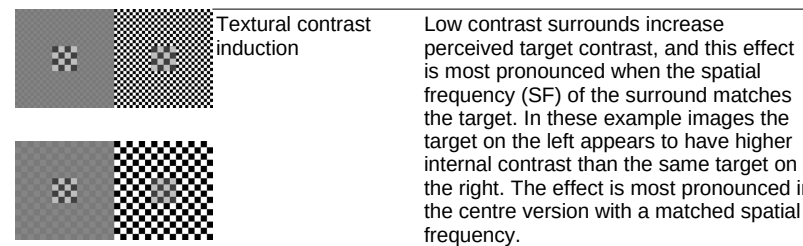
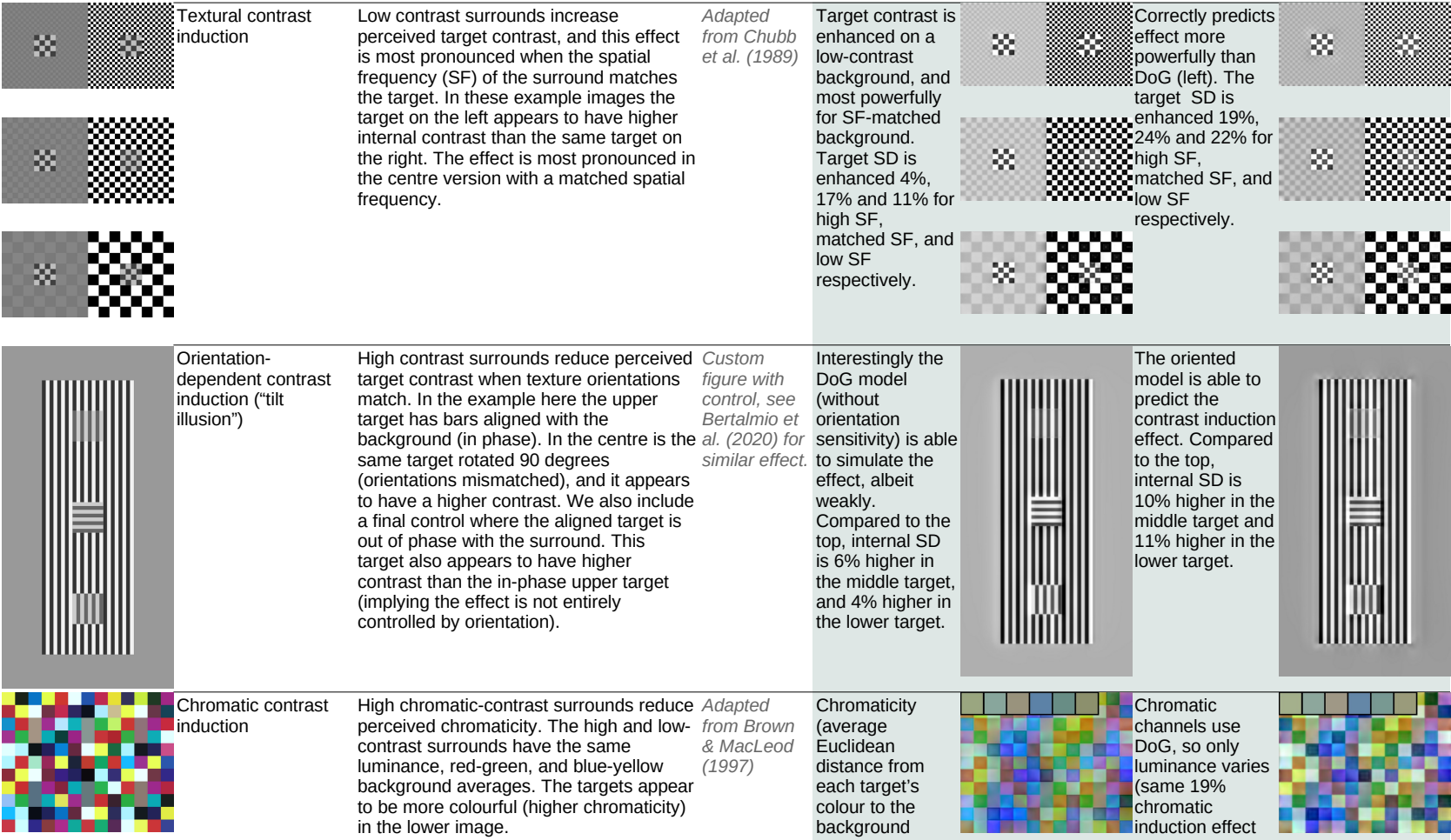

High contrast surrounds reduce perceived Custom Interestingly the target contrast when texture orientations figure with DoG model match. In the example here the upper control, see (without target has bars aligned with the Bertalmio et orientation

background (in phase). In the centre is the al. (2020) for sensitivity) is able same target (inted 00 in cent (orientations mismatched), and it appears to have a higher contrast. We also include a final control where the aligned target is out of phase with the surround. This target also appears to have higher contrast than the in-phase upper target (implying the effect is not entirely controlled by orientation). similar effect. to simulate the effect,

weakly.

Compared to the top, internal SD is $6 \%$ higher in the middle target, and $4 \%$ higher in the lower target.
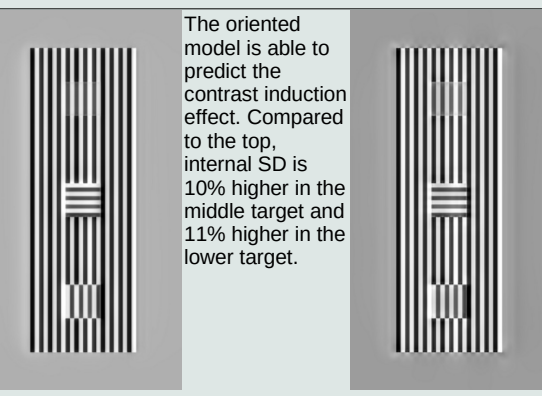

High chromatic-contrast surrounds reduce Adapted pentrast surrounds have the same \& low- from Brown (average
\& MacLeod Euclidea luminance, red-green, and blue-yellow (1997) distance from background averages. The targets appear each target's to be more colourful (higher chromaticity) in the lower image.

colour to the

background average) is $19 \%$ higher on the low contrast background.

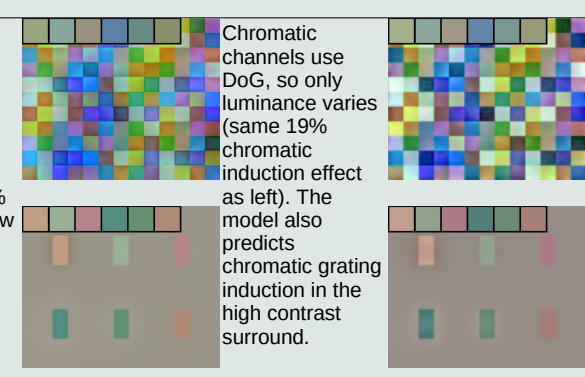

Colour constancy Colour constancy causes surfaces to appear to have the same colour under different lighting colours, generally attributed to chromatic adaptation. The and chromatic mechanism by which this occurs is poorly understood, and models of whole scene averages, local surround averages and local maxima do not explain the $\begin{array}{ll}\text { and chromatic } & \text { mechanism by which this occurs is poorly } \\ \text { adaptation } & \text { effects fully [Kraft \& Brainard (1999)]. }\end{array}$

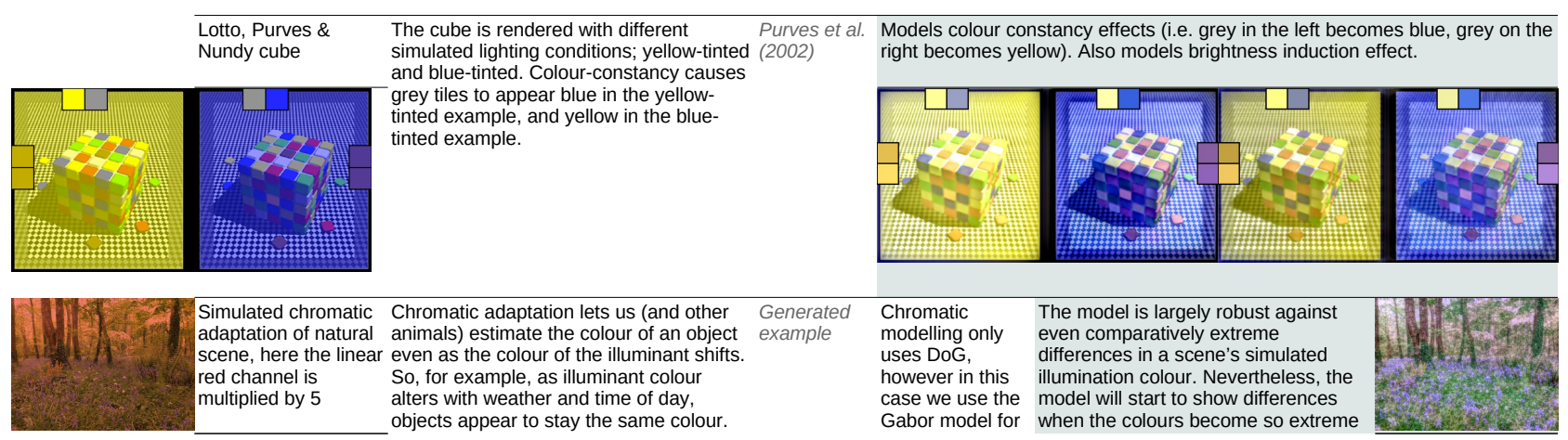


bioRxiv preprint doi: https://doi.org/10.1101/2022.02.22.481414; this version posted February 23, 2022. The copyright holder for this

preprint (which was not certified by peer review) is the author/funder, who has granted bioRxiv a license to display the preprint in perpetuity. It is made available under aCC-BY 4.0 International license.
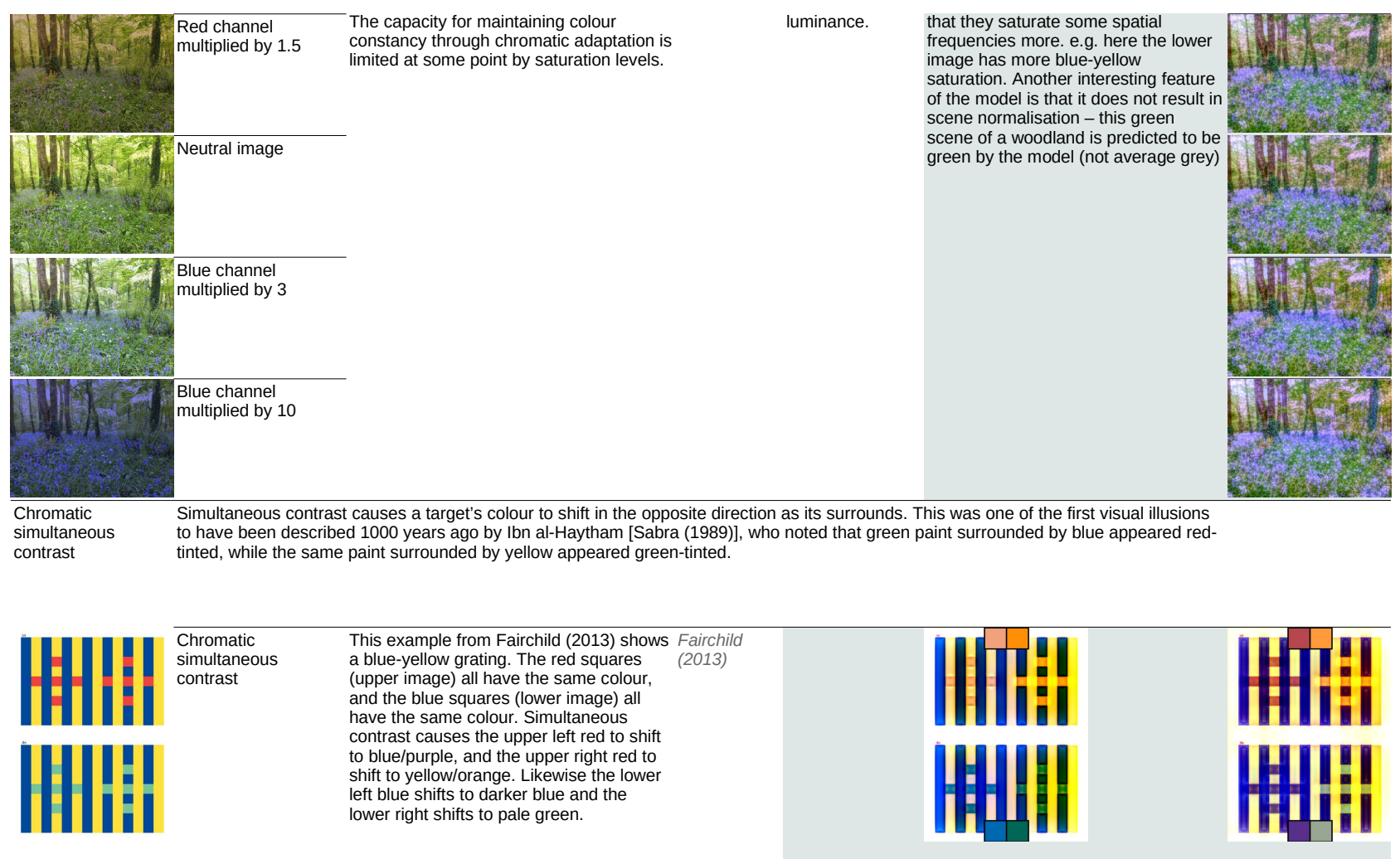

Colour Assimilation Also known as the von Bezold spreading effect, this causes a colour to blend with the colour of its surrounds under certain circumstances. This is the opposite of simultaneous contrast, and early research established the conditions that cause each situation. See Kingdom (2017) for a review.

with 3D spheres
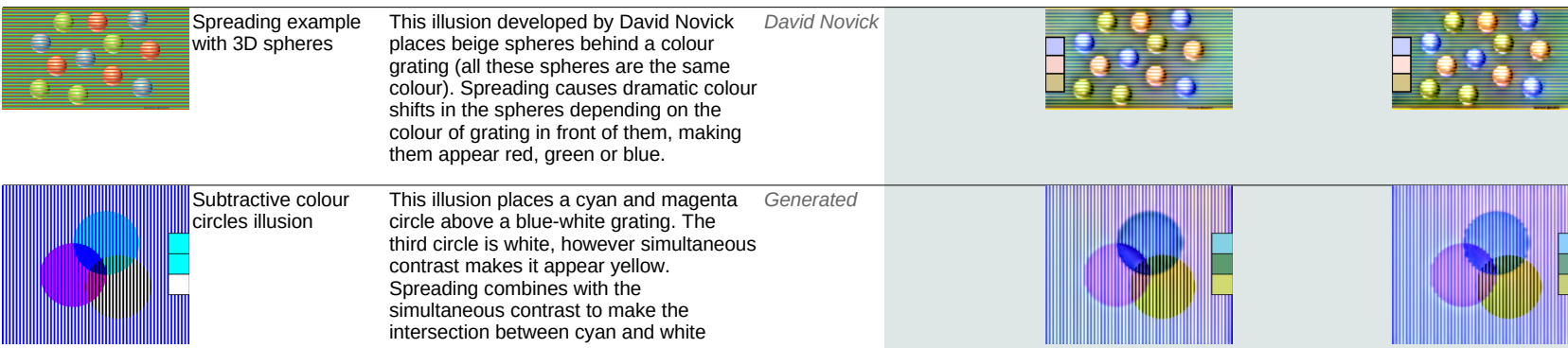

This illusion places a cyan and magenta Generated

circle above a blue-white grating. The

third circle is white, however simultaneous

contrast makes it appear yellow.

Spreading combines with the

simultaneous contrast to make the

intersection between cyan and white appear green.

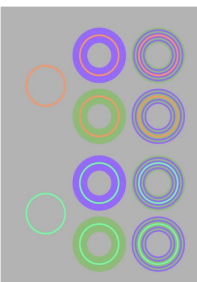

Monnier \& Shevell

powerful (i. asimilation is found to be more

powerful (i.e. colour blending with its

surrounds more powerfully) with a striped

surround than with a solid surround. In

this example the orange ring is identical

all five upper instances, however the

ring surrounded by stripes, than the rings

surrounded by the same solid colours.
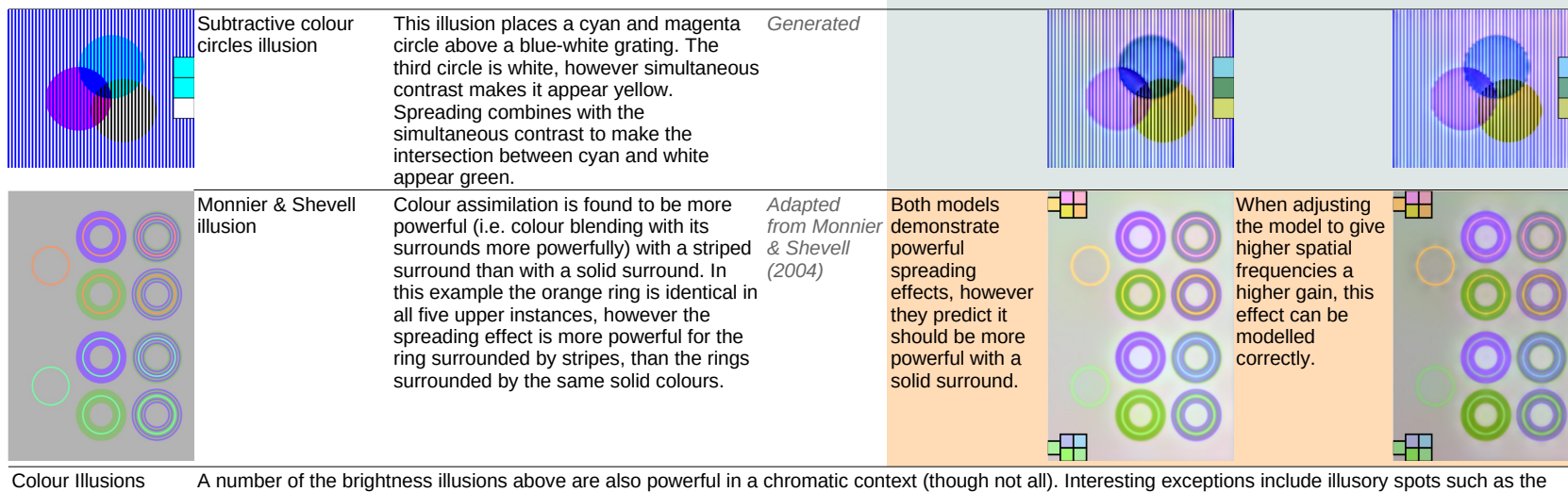

$=$ 田

Adapted Both models

$\exists$

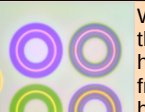

When adjusting $=\square$

powerful

spreading

effects, however

should be more

powerful with a

higher spatial

solid surroun

modelled

correctly.
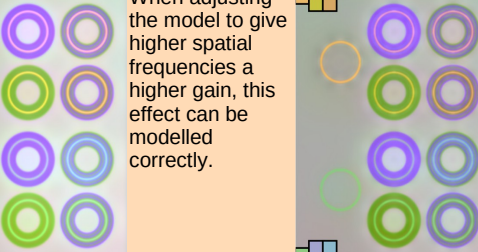

A number of the brightness illusions above are also powerful in a chromatic context (though not all). Interesting exceptions include illusory spots such as the Hermann grid (which our model suggests requires orientation-sensitive filters.

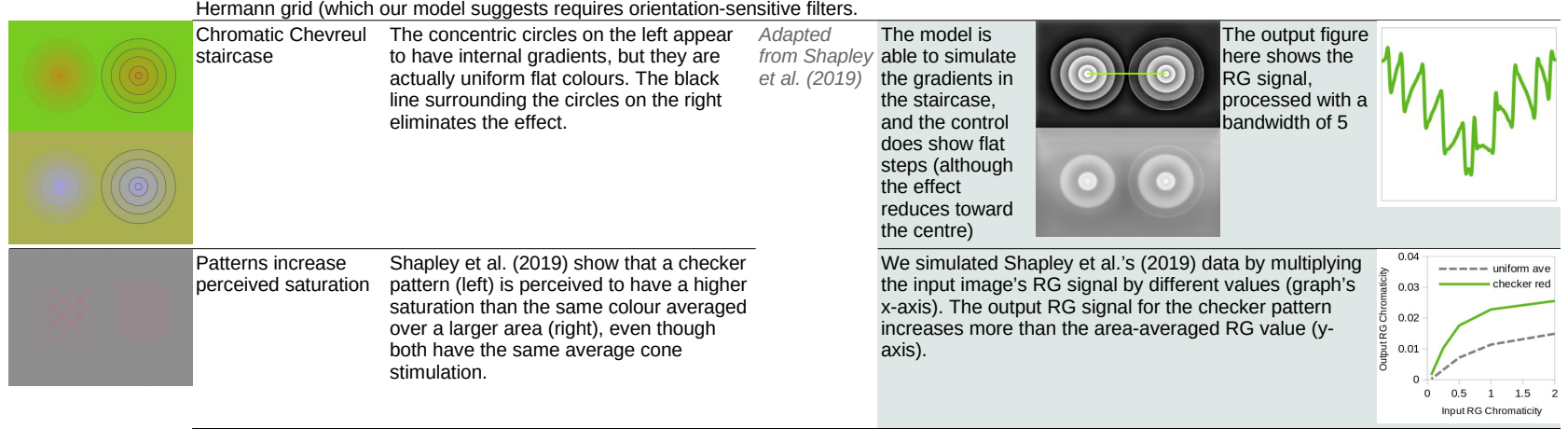

